\title{
Clinical utility of recently identified diagnostic, prognostic, and predictive molecular biomarkers in mature B-cell neoplasms
}

\author{
Arantza Onaindia ${ }^{1}$, L Jeffrey Medeiros ${ }^{2}$ and Keyur P Patel ${ }^{2}$ \\ ${ }^{1}$ Instituto de Investigacion Marques de Valdecilla (IDIVAL)/Hospital Universitario Marques de Valdecilla, \\ Santander, Spain and ${ }^{2}$ Department of Hematopathology, MD Anderson Cancer Center, Houston, TX, USA
}

\begin{abstract}
Genomic profiling studies have provided new insights into the pathogenesis of mature B-cell neoplasms and have identified markers with prognostic impact. Recurrent mutations in tumor-suppressor genes (TP53, BIRC3, $A T M$ ), and common signaling pathways, such as the B-cell receptor (CD79A, CD79B, CARD11, TCF3, ID3), Tolllike receptor (MYD88), NOTCH (NOTCH1/2), nuclear factor-kB, and mitogen activated kinase signaling, have been identified in B-cell neoplasms. Chronic lymphocytic leukemia/small lymphocytic lymphoma, diffuse large B-cell lymphoma, follicular lymphoma, mantle cell lymphoma, Burkitt lymphoma, Waldenström macroglobulinemia, hairy cell leukemia, and marginal zone lymphomas of splenic, nodal, and extranodal types represent examples of B-cell neoplasms in which novel molecular biomarkers have been discovered in recent years. In addition, ongoing retrospective correlative and prospective outcome studies have resulted in an enhanced understanding of the clinical utility of novel biomarkers. This progress is reflected in the 2016 update of the World Health Organization classification of lymphoid neoplasms, which lists as many as 41 mature B-cell neoplasms (including provisional categories). Consequently, molecular genetic studies are increasingly being applied for the clinical workup of many of these neoplasms. In this review, we focus on the diagnostic, prognostic, and/or therapeutic utility of molecular biomarkers in mature B-cell neoplasms.
\end{abstract}

Modern Pathology (2017) 30, 1338-1366; doi:10.1038/modpathol.2017.58; published online 30 June 2017

Mature B-cell neoplasms represent a heterogeneous group of disorders that often have overlapping clinical presentations or morphologic findings or both and therefore can present diagnostic challenges. Furthermore, patients with B-cell neoplasms that show relatively homogeneous pathologic findings can have highly variable clinical outcomes and presenting challenges in clinical management. Recent comprehensive genomic profiling studies have improved our understanding of B-cell lymphomagenesis and have identified novel molecular biomarkers with a diagnostic and prognostic value.

Whereas some B-cell neoplasms such as hairy cell leukemia have a single molecular abnormality (ie BRAFV600E) in $>95 \%$ of cases, other B-cell neoplasms, such as diffuse large B-cell lymphoma (DLBCL), are shown to be genetically highly hetero-

Correspondence: Dr KP Patel, MD, Department of Hematopathology, The University of Texas MD Anderson Cancer Center, 1515 Holcombe Blvd, Unit 149, Houston 77030, TX, USA.

E-mail: kppatel@mdanderson.org

Received 16 February 2017; revised 25 April 2017; accepted 26 April 2017; published online 30 June 2017 geneous containing a number of different molecular aberrations. In addition, the same gene may be involved in more than one type of B-cell neoplasm with variable distribution of mutations or clonal predominance among different neoplasms. For example, BRAF mutations in hairy cell leukemia are restricted to codon V600 and tend to represent the dominant clone as judged by a high variant allele frequency. In comparison, BRAF mutations in chronic lymphocytic leukemia involve exon 11 in addition to codon V600 (exon 15) and can represent a subclonal population. Similarly, in an appropriate clinicopathologic context, $B R A F$ mutations are diagnostic of hairy cell leukemia, but not of chronic lymphocytic leukemia or plasma cell neoplasms. EZH2 mutations in DLBCL primarily involve codon 646 as compared with mutations involving multiple exons in myeloid neoplasms. Within a given tumor type, different biomarkers are shown to be associated with different clinicopathologic features and help explain heterogeneity in outcomes. In patients with chronic lymphocytic leukemia, mutations in MYD88 are seen more commonly in early/untreated cases, whereas mutations in SF3B1, NOTCH1 and TP53 are 
seen more commonly in progressive/treated cases. ${ }^{1}$ Gene mutations can be associated with a specific subtype within a given lymphoma, allowing their use as a surrogate marker for that subtype. Mutations in $C A R D 11, C D 79 A / B$, and $M Y D 88$ are more common in activated B-cell-like DLBCL as compared with germinal center B-cell-like DLBCL, whereas EZH2 mutations are almost restricted to germinal center B-cell-like DLBCL. Interestingly, in DLBCL MYD88 mutations show a site preference being more common in neoplasms arising in immune privileged sites, such as central nervous system $(\sim 75 \%)$ and testis $(\sim 70 \%)$, compared with DLBCL involving lymph nodes $(\sim 15 \%)$ and GI tract $(\sim 10 \%) .^{2}$ In addition to diagnostic and prognostic significance, the mutation profiles also predict response to therapy. Lack of response to standard chemotherapy in patients with chronic lymphocytic leukemia with TP53 mutations and the modifying effect of CXCR4 and MYD88 mutation status on response to ibrutinib in Waldenström macroglobulinemia patients justify pre-treatment screening for these mutations. The emergence of gene mutations during the course of disease, for example, BTK and/or PLCG2 mutations in chronic lymphocytic leukemia post-ibrutinib treatment, provides an important basis for treatment failure.

These important genetic insights are reflected in the evolving classification of B-cell neoplasms as well as consensus patient management guidelines. ${ }^{3-6}$ With increasing integration of molecular biomarkers into the care of patients with B-cell neoplasms, there is a need to develop better tools for diagnosis, identification of novel targets, and monitoring response to therapy. Here, we provide a comprehensive review of recently identified molecular biomarkers in mature B-cell neoplasms and the existing evidence determining their potential clinical utility. Description of well-established cytogenetic biomarkers is kept to a minimum in order to focus on the newly identified molecular biomarkers. Similarly, background information about the lymphoma subtypes has been limited to pertinent details only.

\section{Genomic features and mutated genes of non-Hodgkin lymphomas}

\section{Chronic Lymphocytic Leukemia/Small Lymphocytic Lymphoma)}

Chronic lymphocytic leukemia/small lymphocytic lymphoma represents $18.6 \%$ of NHL cases in the United States. ${ }^{7}$ Chronic lymphocytic leukemia is characterized by a highly heterogeneous clinical course. Several clinical and biological prognostic factors have been identified, such as the Rai and Binet clinical staging systems, specific cytogenetic alterations (-11q, -13q, $-17 p,+12)$, mutational status of the immunoglobulin heavy-chain variable region genes (IGHV), and protein expression (CD38, ZAP-70). ${ }^{8}$ A number of mutations have been reported in $2-10 \%$ of newly diagnosed chronic lymphocytic leukemia cases, including mutations in the tumor-suppressor genes TP53, ATM, or BIRC3; NOTCH1; and SF3B1 involved in the splicing machinery ${ }^{9-15}$ (see Table 3). TP53, NOTCH1, and $S F 3 B 1$ mutations are enriched in patients with specific clinical presentations or high-risk disease, ${ }^{16}$ and are associated with decreased overall survival, and differences in the risk of progression and response to treatment ${ }^{17-21}$ (Tables 1-3 and Figure 1).

Somatic hypermutations and IGHV region gene utilization. Using the widely accepted (although arbitrary) cutoff of $2 \%$ mutations in the IGHV genes, mutated $(>2 \%)$ and unmutated chronic lymphocytic leukemia cases show a distinctive behavior. Patients with unmutated chronic lymphocytic leukemia have a worse clinical outcome as these neoplasms are associated with adverse prognostic factors. Furthermore, usage of VH3-21 is an adverse prognostic marker that is independent of IGHV mutation status. ${ }^{4,22}$ Unmutated chronic lymphocytic leukemia cases are associated with high levels of expression of CD38 $(\geq 30 \%)$ and ZAP-70 $(\geq 20 \%)$, which can be used as surrogates for unmutated status.

Ataxia-telangiectasia mutated. Missense Ataxiatelangiectasia mutated (ATM) mutations leading to kinase inactivation are present in $12 \%$ of chronic lymphocytic leukemia patients and may be important in predicting treatment failure ${ }^{21}$ (Figure 1 and Table 1). Deletion of chromosome $11 \mathrm{q}$ was recognized initially as a recurrent karyotypic abnormality acquired during the course of disease in patients with progressive chronic lymphocytic leukemia. ATM mutations are identified in $20 \%$ of patients with advanced chronic lymphocytic leukemia, and are associated with bulky lymphadenopathy and a poorer outcome in relatively young ( $<55$ years) patients. ${ }^{16}$ Mutations are associated with a shorter time to first treatment, disease progression (23.5 months for $100 \%$ of ATM-deleted patients and 30 months for $62.5 \%$ of patients with ATM point mutations), as well as a shorter treatment-free interval (64.2 months in patients with ATM alterations) $^{23}$ (Table 1 and Figure 1). ATM inactivation (via mutation or deletion) is associated with refractoriness to chemotherapy through failure to activate p53 and p21 ${ }^{24-26}$ (Tables 1-3 and Figure 1). Small molecules that inhibit the MDM2-p53 interaction increase p53 levels and induce apoptosis in chronic lymphocytic leukemia cases with deletion of $A T M{ }^{27}$ Similar approaches may be useful therapeutically.

Baculovial IAP repeat containing 3. The majority of Baculovial IAP repeat containing 3 (BIRC3) (previously known as API2 or CIAP2) mutations described in chronic lymphocytic leukemia are of the inactivating type: whole-gene deletions, frameshifts, 
Table 1 Clinical significance of the main driver mutations in chronic lymphocytic leukemia

\begin{tabular}{|c|c|c|c|c|c|c|}
\hline Mutated gene & $A T M$ & BIRC3 & MYD88 & NOTCH1 & $S F 3 B 1$ & TP53 \\
\hline $\begin{array}{l}\text { Chromosome } \\
\text { location }\end{array}$ & $11 q 22-q 23$ & $11 \mathrm{q} 22$ & $3 p 22$ & $9 q 34.3$ & $2 \mathrm{q} 33.1$ & $17 \mathrm{p} 13.1$ \\
\hline $\begin{array}{l}\text { Typical } \\
\text { mutation }\end{array}$ & Missense & $\begin{array}{l}\text { Deletions, } \\
\text { frameshifts or } \\
\text { nonsense mutations }\end{array}$ & $\begin{array}{l}\text { Single-nucleotide } \\
\text { L265P missense } \\
\text { substitution }\end{array}$ & $\begin{array}{l}\text { Frameshift or nonsense } \\
\text { events clustering within exon } \\
34 \text { (7545delCTdeletion) }\end{array}$ & $\begin{array}{l}\text { Missense mutations } \\
\text { (codons 662, 666, } \\
\text { and 700) }\end{array}$ & $\begin{array}{l}\text { Non-synonymous } \\
\text { mutations in exons } \\
4-8 \text { (codons 272-287) }\end{array}$ \\
\hline Frequency & $\begin{array}{l}12 \% \text { of newly } \\
\text { diagnosed patients }\end{array}$ & $\begin{array}{l}4 \% \text { of newly } \\
\text { diagnosed patients } \\
\text { Enriched mutations } \\
\text { in fludarabine- } \\
\text { resistant-patients } \\
(24 \%)\end{array}$ & $\begin{array}{l}1.5-4 \% \text { of newly } \\
\text { diagnosed patients }\end{array}$ & $\begin{array}{l}5-10 \% \text { newly diagnosed cases } \\
\text { Enriched frequency in } \\
\text { progressive cases }(15-20 \%)\end{array}$ & $\begin{array}{l}4-12 \% \text { in early CLL } \\
\text { Enriched frequency in } \\
\text { disease progression } \\
(17-24 \%)\end{array}$ & $\begin{array}{l}4-10 \% \text { of newly } \\
\text { diagnosed patients }\end{array}$ \\
\hline $\begin{array}{l}\text { Clinical } \\
\text { presentation }\end{array}$ & Bulky lymphadenopathy & $\begin{array}{l}\text { Correlation with } \\
\text { unmutated IGHVs, } \\
\text { trisomy 12,11q } \\
\text { deletions. } \\
\text { Exclusive from } \\
\text { TP53 mutation }\end{array}$ & $\begin{array}{l}\text { Association with } \\
\text { favorable prognostic } \\
\text { factors: younger age } \\
\text { ( } \leq 50 \text { years), low } \\
\text { expression of CD38 } \\
\text { and ZAP-70, higher } \\
\text { frequency of mutated } \\
\text { IGHV }\end{array}$ & $\begin{array}{l}\text { Correlate with adverse } \\
\text { clinical parameters: IGHV } \\
\text { unmutational status, trisomy } \\
\text { 12, high CD38/ZAP-70 }\end{array}$ & $\begin{array}{l}\text { Association with adverse } \\
\text { prognostic factors } \\
\text { (IgHV unmutated status, } \\
\text { advanced Binet stages, } \\
\text { higher levels of CD38 } \\
\text { expression) } \\
\text { Association with } \\
\text { 11q23 deletions } \\
\text { Less frequently present in } \\
\text { association with del(13q); } \\
\text { mutually exclusive trisomy } \\
12\end{array}$ & $\begin{array}{l}\text { Association with } \\
\text { NOTCH1 and SF3B1 } \\
\text { mutation } \\
\text { Adverse prognostic } \\
\text { factors IgHV unmutated } \\
\text { status, advanced Binet } \\
\text { stages, higher levels of } \\
\text { CD38 expression) }\end{array}$ \\
\hline Outcome & Shorter TTT and PFS. & Shorter OS & $\begin{array}{l}\text { No difference with the } \\
\text { age-matched healthy } \\
\text { population }\end{array}$ & $\begin{array}{l}\text { High-risk of lymphomatous } \\
\text { progression to aggressive } \\
\text { DLBCL in RS (present in } \\
\text { 90\% of the cases } \\
\text { Shorter OS, PFS and TTT }\end{array}$ & $\begin{array}{l}\text { Shorter TTT and OS } \\
\text { Risk stratification of } \\
\text { patients with other } \\
\text { cytogenetic abnormalities } \\
\text { (shorter OS in patients } \\
\text { with del(11q) and del13q) }\end{array}$ & $\begin{array}{l}\text { Increased risk of } \\
\text { progression to aggressive } \\
\text { B-cell lymphoma } \\
\text { transformation } \\
\text { (40\% frequency in RS) } \\
\text { Shorter TTT, PFS, OS }\end{array}$ \\
\hline $\begin{array}{l}\text { Treatment } \\
\text { response }\end{array}$ & $\begin{array}{l}\text { Chemo-refractoriness } \\
\text { to alkylating agent or } \\
\text { purine analog treatment }\end{array}$ & $\begin{array}{l}\text { Chemo- } \\
\text { refractoriness } \\
\text { to fludarabine- } \\
\text { containing regimens }\end{array}$ & No treatment needed & $\begin{array}{l}\text { Decreased benefit of } \\
\text { addition of rituximab to } \\
\text { fludarabine treatment } \\
\text { Benefit from anti-CD52 } \\
\text { treatment }\end{array}$ & $\begin{array}{l}\text { Chemo-refractoriness to } \\
\text { fludarabine-containing } \\
\text { regimens }\end{array}$ & $\begin{array}{l}\text { Chemo-refractoriness } \\
\text { to fludarabine-containing } \\
\text { regimens }\end{array}$ \\
\hline
\end{tabular}

Abbreviations: IGHV: immunoglobulin heavy-chain variable region genes; OS: overall survival; PFS: progression-free survival; RS: Richter Syndrome; TTT: time to first treatment. 
Table 2 Morphological, immunophenotypic, cytogenetic, and molecular characteristics of the main subtypes of B-cell lymphoma

\begin{tabular}{|c|c|c|c|c|c|c|c|c|c|c|c|c|}
\hline & $C L L / S L L$ & $F L$ & $D L B C L$ & $B L$ & $M C L$ & $S M Z L$ & $M Z L$ & $L P L / W M$ & $H C L$ & $H C L-V$ & $M M$ & \\
\hline Morphology & $\begin{array}{l}\text { Monomorphic } \\
\text { small, round to } \\
\text { slightly irregular B } \\
\text { lymphocytes } \\
\text { admixed with } \\
\text { prolymphocytes } \\
\text { and paraimmuno- } \\
\text { blasts }\end{array}$ & $\begin{array}{l}\text { Follicle center } \\
\text { B-cells (centrocytes } \\
\text { and centroblasts) } \\
\text { with a partially } \\
\text { follicular pattern }\end{array}$ & $\begin{array}{l}\text { Large B lymphoid } \\
\text { cells with nuclear } \\
\text { size twice a } \\
\text { lymphocyte, that } \\
\text { has a diffuse } \\
\text { growth pattern }\end{array}$ & $\begin{array}{l}\text { Monomorphic } \\
\text { medium-sized } \\
\text { transformed cells }\end{array}$ & $\begin{array}{l}\text { Monomorphic small- } \\
\text { to medium-sized } \\
\text { lymphoid cells with } \\
\text { irregular nuclear } \\
\text { contours }\end{array}$ & $\begin{array}{l}\text { Small lympho- } \\
\text { cytes replacing } \\
\text { the splenic white } \\
\text { pulp with a } \\
\text { prominent } \\
\text { marginal zone }\end{array}$ & $\begin{array}{l}\text { Monocytoid } \\
\text { tumor cells } \\
\text { surrounding } \\
\text { reactive } \\
\text { follicles and } \\
\text { expanding } \\
\text { into the inter- } \\
\text { follicular areas }\end{array}$ & $\begin{array}{l}\text { Small B } \\
\text { lymphocytes, } \\
\text { plasmacytoid } \\
\text { lymphocytes } \\
\text { and plasma } \\
\text { cells }\end{array}$ & $\begin{array}{l}\text { Small mature } \\
\text { B lymphoid } \\
\text { cells with } \\
\text { oval nuclei } \\
\text { and } \\
\text { abundant } \\
\text { cytoplasm } \\
\text { with 'hairy' } \\
\text { projections }\end{array}$ & $\begin{array}{l}\text { Prolymphocytes } \\
\text { and hairy cells }\end{array}$ & $\begin{array}{l}\text { Atypical plasma } \\
\text { cells usually } \\
\text { occur in } \\
\text { interstitial } \\
\text { clusters, and focal } \\
\text { nodules or diffuse } \\
\text { sheets of plasma } \\
\text { cells }\end{array}$ & \\
\hline Immunophenotype & $\begin{array}{l}\text { CD20+,CD5+, CD23 } \\
+, \text { LEF1+, cyclin } \\
\text { D1 - }\end{array}$ & $\begin{array}{l}\text { CD20+, CD5 -, } \\
\text { CD10+, BCL6+, } \\
\text { BCL2+ }\end{array}$ & $\begin{array}{l}\text { CD20, CD79a+. } \\
\text { CD30 } \pm \text { and } \\
\text { CD5 } \pm \\
\text { A combination } \\
\text { of CD10, BCL6 } \\
\text { and MUM1 } \\
\text { expression are } \\
\text { used to classify } \\
\text { the cases into the } \\
\text { ABC or GCD } \\
\text { subgroups }\end{array}$ & $\begin{array}{l}\text { CD20+,CD5 - } \\
\text { CD10+, BCL2 - } \\
\text { TdT - }\end{array}$ & $\begin{array}{l}\text { CD20+,CD5+, } \\
\text { CD23-, Cyclin D1+ }\end{array}$ & $\begin{array}{l}\text { CD20+,CD5 -, } \\
\text { cD10 -, CD103 -, } \\
\text { cytoplasmic Ig- }\end{array}$ & $\begin{array}{l}\text { CD5-, cD10-, } \\
\text { CD103-, } \\
\text { cytoplasmic } \\
\text { Ig- }\end{array}$ & $\begin{array}{l}\text { CD20+, Igm+, } \\
\text { CD5, CD10, } \\
\text { CD23 }\end{array}$ & $\begin{array}{l}\text { CD20+,CD22 } \\
\text { +, CD11ct, } \\
\text { CD103+, } \\
\text { CD25+, } \\
\text { CD123+,Tbet } \\
\text { +, Annexin } \\
\text { A1+, DBA44 } \\
\text { +,CD5-, } \\
\text { CD10- }\end{array}$ & $\begin{array}{l}\mathrm{Cd} 20+, \mathrm{Cd} 25-, \\
\text { CD123-, } \\
\text { CD200- }\end{array}$ & $\begin{array}{l}\text { CD20 - CD79a+, } \\
\text { VS38C+, CD138+ } \\
\text { and strong CD38+ } \\
\text { CD19- } \\
\text { CD56+ }\end{array}$ & \\
\hline $\begin{array}{l}\text { Cytogenetics, } \\
\text { chromosomal } \\
\text { abnormalities }\end{array}$ & & $\begin{array}{l}\mathrm{t}(14 ; 18)(\mathrm{q} 32 ; \mathrm{q} 21) \\
(80 \%), \text { loss of } 1 \mathrm{p}, \\
6 \mathrm{q}, 10 \mathrm{q} \text { and } 17 \mathrm{p} \text { and } \\
\text { gains of chromo- } \\
\text { somes1, 6p, } 7,8 \text {, } \\
12 \mathrm{q}, \mathrm{X} \text { and } 18 \mathrm{q} / \mathrm{dup}\end{array}$ & $\begin{array}{l}\mathrm{t}(14 ; 18), 3 \mathrm{q} \\
\text { gain/amplifica- } \\
\text { tion, 9p gain/ } \\
\text { amplification, } \\
\text { 12q12 }\end{array}$ & $\mathrm{t}(8 ; 14)(\mathrm{q} 24 ; \mathrm{q} 32)$ & $\begin{array}{l}\mathrm{t}(11 ; 14)(\mathrm{q} 13 ; \mathrm{q} 32) \\
\text { Gains of 3q26, } \\
\text { 7p21, 8q24 (MYC), } \\
\text { trisomy 12 } \\
\text { Losses of 1p13-p31, } \\
\text { 6q23-q27, 9p21, } \\
\text { 11q22-q23, 13q11- } \\
\text { q13, 13q14-q34 and } \\
\text { 17p13 }\end{array}$ & $\begin{array}{l}\text { Loss of } \\
\text { chromosome } \\
7 \mathrm{q} 31 \text {, trisomy } 3 \mathrm{q}\end{array}$ & $\begin{array}{l}\text { Trisomies 3, 18, } \\
\text { and } 7\end{array}$ & & & & $\begin{array}{l}\text { del17p13, t(11;14) } \\
\text { (q13;q32), t4;14) } \\
\text { (p16;q32) and t } \\
\text { (14;16)(q32;q23), } \\
\text { chromosome 13 } \\
\text { deletion, and } \\
\text { chromosome 1 } \\
\text { amplification }\end{array}$ & \\
\hline \multirow[t]{3}{*}{$\begin{array}{l}\text { Molecular } \\
\text { alterations }\end{array}$} & Diagnostic & $\begin{array}{l}\text { IgH gene } \\
\text { rearrangements }\end{array}$ & $\begin{array}{l}\text { IgH gene } \\
\text { rearrangements, t } \\
(14 ; 18)(\mathrm{q} 32 ; \mathrm{q} 21), \\
\text { TNFRSF14 } \\
\text { mutations4 }\end{array}$ & $\begin{array}{l}\text { IgH gene } \\
\text { rearrangements, } \\
\text { CARD11, CD79A, } \\
\text { CD79B, PIM1. } \\
\text { EZH2 }\end{array}$ & $\begin{array}{l}\text { Ig rearrangements } \\
\text { with somatic } \\
\text { hypermutationID3, } \\
\text { TCF3, MYC, } \\
\text { SMARCA4 }\end{array}$ & $\begin{array}{l}\text { IgH gene } \\
\text { rearrangements } \\
\text { CCND1 } 1^{\text {a }}, A T M\end{array}$ & $K L F 2$ & $\begin{array}{l}\text { IgH rearrange- } \\
\text { ments, PTPRD, } \\
\text { KMT2D }\end{array}$ & MYD88 ${ }^{a}$ & BRAFV600E & MAP2K1, ТP53 & KRAS, NRAS \\
\hline & Prognostic & $\begin{array}{l}\text { Somatic } \\
\text { hypermutations }{ }^{\mathrm{a}} \text {, } \\
\text { VH family usage a, } \\
\text { ATM, BIRC3, TP53 } \\
\text { a b, NOTCH1, } \\
\text { SF3B1 }\end{array}$ & $\begin{array}{l}B C L 6 \\
\text { rearrangements } \\
(5-15 \%) \text { in } \\
\text { association with } \\
\text { grade 3B.TP53 } \\
\text { B2M, CCND3 } \\
\text { GNA13, S1PR2, } \\
\text { and P2RY8 }\end{array}$ & $\begin{array}{l}\text { CARD11, CD79A, } \\
\text { CD79B, PIM1, } \\
\text { STAT6, MYC, } \\
\text { MYDD8, PIK3CD, } \\
\text { MLL3, TP53, } \\
\text { SOC1, PRDM1 }\end{array}$ & GNA13,TP53 & $\begin{array}{l}\text { CCND1, CDK4, } \\
\text { CDKN2B, } \\
\text { MAP3K314, } \\
\text { TP53, NOTCH1 } \\
\text { and NOTCH2 }\end{array}$ & NOTCH2, TP53 & & $\begin{array}{l}\text { MYD88 }{ }^{\mathrm{a}}, \\
\text { CXCR } 4^{\mathrm{a}}\end{array}$ & & MAP2K1 & $\begin{array}{l}\text { Gene } \\
\text { expression } \\
\text { profiling } \\
\text { signature, } \\
\text { CCND1, } \\
\text { TP53, ATM, } \\
\text { ATR, FGFR3 }\end{array}$ \\
\hline & Predictive & BTK, $P L C \gamma 2$, TP5 $3^{\mathrm{ab}}$ & $\mathrm{EZH} 2, T P 53$ a & $\begin{array}{l}\text { CARD11, CD79A, } \\
\text { CD79B, PIM1, } \\
\text { PIK3CD, TP53 }\end{array}$ & ID3, TP53, TCF3 & $\begin{array}{l}\text { MAP3К } 314, \\
\text { RELA }\end{array}$ & & & $\mathrm{CXCR} 4^{\mathrm{a}}$ & BRAFV600E & & $\begin{array}{l}\text { CCND1, } \\
\text { TP53, FGFR3, } \\
\text { KRAS, NRAS }\end{array}$ \\
\hline
\end{tabular}

Abbreviations: BL: Burkitt lymphoma; CLL/SLL: chronic lymphocytic leukemia (CLL)/small lymphocytic lymphoma (SLL); DLBCL: diffuse large B-cell lymphoma; FL: follicular lymphoma; HCL: hairy cell leukemia; LPL: lymphoplasmacytic lymphoma.

'2016 WHO Update.

'2016 WHCN.

${ }^{b}$ Eric guidelines. 
Table 3 Function and location of the main genes mutated in B-cell lymphomas

Gene name Function

ARID1A (1p36.11)

ARID1A encodes a member of the SWI/SNF family, whose members have helicase and ATPase activities and are thought to regulate transcription of certain genes by altering the chromatin structure around those genes. The encoded protein is part of the large ATP-dependent chromatin remodeling complex SNF/SWI, which is required for transcriptional activation of genes normally repressed by chromatin.

ATM (11q22-q23) ATM is a member of the phosphatidylinositol-3 kinase (PI3K) family of genes. It encodes a protein kinase that is a central component of the DNA damage signaling pathway, activating cell-cycle checkpoints, and inducing apoptosis in response to DNA double-strand breaks (DSBs). ${ }^{55}$

BTK (Xq22.1) The Bruton's tyrosine kinase (BTK) codifies a protein that phosphorylates PLCr2, promoting the production of diacylglycerol (DAG) and IP3, which IP3 activate protein kinase $\mathrm{C} \beta$ (PKC $\beta$ ), leading to CARD11 phosphorylation and NF- $\kappa$ B signaling initiation. ${ }^{33,139}$

CARD11 (7p22.2) CARD11 encodes a multi-domain protein that takes part into a signaling complex required for NF- $\kappa \mathrm{B}$ signaling downstream of the BCR receptors.

CCND1 (11q13) CCND1 (Cyclin D1) forces the constitutive overexpression of cyclin D1, which is absent in normal B lymphocytes, and deregulates the cell cycle at the G1/S phase transition. ${ }^{163}$ The role of CCND1 in promoting MCL lymphomagenesis is related to its function in the cell cycle regulating the cyclin-dependent kinases CDK4 and CDK6. CCND1 binding to CDK4/6 activates the transcription factor E2F by phosphorylating its inhibitor, retinoblastoma 1 (RB1), and further promotes cyclin E/CDK2 activation to trigger entry into the $\mathrm{S}$ phase of the cell cycle ${ }^{163}$

CCND2 (12p13.32) CCND2 encodes a cyclin that forms a complex with CDK4 or CDK6 and functions as a regulatory subunit of the complex, whose activity is required for cell cycle G1/S transition. This protein has been shown to interact with and be involved in the phosphorylation of tumor-suppressor protein $\mathrm{Rb}$.

CD79A (19q13.2) CD79B (17q23.3) CD79A is a transmembrane protein with a cytoplasmic domain that contains multiple phosphorylation sites including a conserved dual tyrosine binding motif, termed immunotyrosine-based activation motif (ITAM). CD79A has several cysteine residues, one of which forms covalent bonds with CD79b, encoded by CD79B, located in chromosome 17q23.3. Association of the CD79A/B heterodimer with the immunoglobulin heavy chain is required for surface expression of the BCR, and BCR induced calcium flux and protein tyrosine phosphorylation in response.

CDK4 (12q14.1) CDK4 is a member of the Ser/Thr protein kinase family. CDK4 is a catalytic subunit of the protein kinase complex that is important for cell-cycle G1 phase progression. The activity of this kinase is restricted to the G1-S phase, which is controlled by the regulatory subunits D-type cyclins and CDK inhibitor p16(INK4a). CDK4 is responsible for the phosphorylation of retinoblastoma gene product $(\mathrm{Rb})$.

CDKN2A (9p21.3) The cyclin-dependent kinase inhibitors 2A, B and C are located in chromosome 9 and 1 and function as inhibitors $C D K N 2 B(9 \mathrm{p} 21.3)$

CDKN2C (1p32.3) of CDK4. This genes encodes a cyclin-dependent kinase inhibitor, which forms a complex with CDK4 or CDK6, and prevents the activation of the CDK kinases, thus the encoded protein functions as a cell growth regulator that controls cell-cycle G1 progression.

CREBBP (16p13.3) CREBBP,is involved in the transcriptional coactivation of many different transcription factors. The protein encoded by $C R E B B P$ is an intrinsic histone acetyltransferase and also acts as a scaffold to stabilize additional protein interactions with the transcription complex. This protein acetylates both histone and non-histone proteins.

CXCR4 (2q22) The Chemokine (C-X-C motif) receptor type 4 (CXCR4) transduces a signal upon ligand activation by increasing intracellular calcium ion levels and enhancing MAPK1/MAPK3 activation. The CXCR4 mutations associated with WM are clustered in the C-terminus of the protein and interfere with normal receptor internalization required to downregulate CXCR4-mediated signaling. As a result of the mutations, there is an increase in the number of CXCR4 receptors at the cell membrane, leading to increased activation of the signaling pathway.

EGR (5q31.2) EGR1 belongs to the EGR family of C2H2-type zinc-finger proteins. It is a nuclear protein and functions as a transcriptional regulator. The products of target genes it activates are required for differentitation and mitogenesis. EP300 (22q13.2) The E1A Binding Protein P300 (EP300) encodes the adenovirus E1A-associated cellular p300 transcriptional
coactivator protein. It functions as histone acetyltransferase that regulates transcription via chromatin remodeling and is important in the processes of cell proliferation and differentiation. It mediates cAMP-gene regulation by binding specifically to phosphorylated CREB protein.

EZH2 (7q36.1) EZH2 codifies the catalytic subunit of PRC2, an histone methyltransferase that catalyzes trimethylation of lysine 27 on histone H3 (H3K27me3), a repressive chromatin mark. ${ }^{191} \mathrm{H} 3 \mathrm{~K} 27 \mathrm{me} 3$ is associated with transcriptional silencing and results in the repression of a large number of genes, including the cell-cycle inhibitors encoded by the CDKN1A and CDKN2A/B genes. ${ }^{195,196}$

FGFR3 (4p16.3) FGFR3 encodes a member of the fibroblast growth factor receptor (FGFR) family, which extracellular portion of the protein interacts with fibroblast growth factors, setting in motion a cascade of downstream signals, ultimately influencing mitogenesis and differentiation.

HIST1H1C/D/E Histone Cluster $1 \mathrm{H} 1$ Family Members C, D, and E $(H I S T 1 H 1 C / D / E)$ bind to linker DNA between nucleosomes (6p22) forming the macromolecular structure known as the chromatin fiber. Histones H1 are necessary for the condensation of nucleosome chains into higher-order structured fibers. Acts also as a regulator of individual gene transcription through chromatin remodeling, nucleosome spacing, and DNA methylation.

KLF2 (19p.13) The Krüppel-like factor 2 (KLF2) zinc-finger gene codifies for a transcription factor important for the homeostasis and differentiation of peripheral B-cell subsets. ${ }^{197}$ In normal lymphocytes, KLF2 binds the promoter and regulates the expression of genes involved in cell-cycle/apoptosis (CDKN1A/p21) and cell trafficking (S1PR1,SELL/CD62L, ITGB7/ $\beta 7$-integrin, and CXCR5). ${ }^{197}$

ID3 (1p36.12) DNA-binding protein inhibitor ID3 is a protein that in humans is encoded by the ID3 gene. Members of the ID family of helix-loop-helix (HLH) proteins lack a basic DNA-binding domain and inhibit transcription through formation of nonfunctional dimers that are incapable of binding to DNA. In resting conditions, the TCF3 transcription factor is maintained inactive through heterodimerization with ID3.

KMTD (12q.13) KMT2D (Lysine Methyltransferase 2D), also called MLL2, is a tumor-suppressor histone-modifier in which point mutations have been reported to affect a residue within either the catalytic SET domain, the FYRC domain (FY-rich carboxy-terminal domain) or PHD zinc-finger domains, leading to its inactivation. ${ }^{80}$ 
Table 3 (Continued)

Gene name Function

MYD88 (3p22)

The MYD88 or myeloid differentiation primary response 88 gene encodes for an adapter protein that acts as a signal transducer in the IL-1, IL-18, and Toll-like receptor signaling pathways, as part of the innate immune response. The MYD88 protein consists of an N-terminal death domain, a linker region, and a C-terminal TIR domain, which may mediate contact with TLR TIR domains upon signaling activation inducing NF- $k$ B signaling activation. ${ }^{149}$

NOTCH1 (9q34.3) NOTCH1 is a transmembrane receptor that regulates critical cellular functions, such as proliferation, apoptosis, and differentiation, and is associated with tumorigenesis. NOTCH1 signaling is initiated when a ligand from the Jagged or Delta families binds the receptor and induces a cascade of proteolytic processes that results in the release and nuclear translocation of the NOTCH1 intracellular domain (NCID). This, in conjunction with the transcription factor CBF1/RBP-Jk, leads to the activation or repression of its target genes.

PLCG2 (16q23.3) PLCG2 is a transmembrane signaling enzyme that catalyzes the conversion of 1-phosphatidyl-1D-myo-inositol 4,5bisphosphate to 1D-myo-inositol 1,4,5-trisphosphate (IP3) and diacylglycerol (DAG) using calcium as a cofactor. IP3 and DAG are second messenger molecules important for transmitting signals from growth factor receptors and immune system receptors across the cell membrane.

POT1 (7q31.33) The protection of telomeres 1 (POT1) gene encodes a protein that functions as a member of a multiprotein complex that binds to the TTAGGG repeats of telomeres, regulating telomere length and protecting chromosome ends from illegitimate recombination, catastrophic chromosome instability, and abnormal chromosome segregation.

PTPRD (9p23) The receptor-type-protein-tyrosine-phosphatase-d (PTPRD) is a tumor-suppressor gene involved in cell growth regulation and affected by somatic mutations in solid cancers, promoting tumorigenesis through Y705-phospho STAT3 activation. ${ }^{53}$

$R B 1$ (13q14.2) The RB transcriptional corepressor 1 (RB1) gene is a tumor-suppressor gene coding for a protein that also stabilizes constitutive heterochromatin to maintain the overall chromatin structure.

SMARCA4

(19p13.2)

SF3B1 (2q33.1)

The SWI/SNF related, matrix associated, actin-dependent regulator of chromatin, subfamily a, member 4

(SMACA4) gene encodes a protein that is part of the large ATP-dependent chromatin remodeling complex SNF/ SWI, which is required for transcriptional activation of genes normally repressed by chromatin. In addition, this protein can bind BRCA1, as well as regulate the expression of the tumorigenic protein CD44.

SF3B1 is located on chromosome 2q33.1 and encodes for a critical component of the RNA splicing machinery that achieves successful transcription and guarantees the functional diversity of protein species using alternative spicing.

TCF3 (19p13.1) Transcription factor 3 (E2A immunoglobulin enhancer-binding factors E12/E47), also known as TCF3, is a member of the E protein (class I) family of helix-loop-helix (HLH) transcription factors. The 9aa transactivation domains (TAD) of E proteins bind to the KIX domain of general transcriptional mediator CBP. E proteins activate transcription by binding to regulatory E-box sequences on target genes as heterodimers or homodimers, and are inhibited by heterodimerization with inhibitor of DNA-binding (class IV) HLH proteins.

TP53 (17p13.1) The TP53 gene is a crucial tumor-suppressor that mediates cell-cycle arrest, DNA repair, apoptosis, senescence, and autophagy under cellular stress via transcription dependent and independent activity in the nucleus and cytoplasm. ${ }^{81,82}$ TP53 dysfunction is implicated in lymphomagenesis and disease progression, ${ }^{83}$ and normal function of p53 is crucial for tumor suppression. ${ }^{86,87}$ The human p53 gene contains 393 codons and the p53 protein this gene produces is commonly divided into five domains: an RNA polymerase transactivating, domain, a prolinerich domain, a DNA-binding domain, a tetramerization domain, and a carboxy-terminal regulatory domain. TP53 DNA-binding domain (DBD) is divided into three loops: L1 (codons 112-141), L2 (codons 163-195), and L3 (codons 236-251), and 2 loop-sheet-helix regions (codons 119-135; 272-287). Loops 1 and 3 and the Loop-SheetHelix (LSH) region from codons 272 to 287 make direct contact with the DNA regulated by the p53 transcription factor. Loop 2 is required for folding and stabilization of this DBD and is not in direct contact with DNA.

Inactivation on TP53 is most commonly the result of non-synonymous mutations frequently clustered in the DNAbinding domain (DBD), encoded by exons 4-8 of the TP53 gene, ${ }^{88,89}$ which is the most important one for its activity. ${ }^{16,90,214}$

or nonsense mutations resulting in truncation of cIAP2 prior to the C-terminal RING domain. ${ }^{28-30}$ BIRC3 inactivation leads to constitutive activation of the non-canonical nuclear factor- $k \mathrm{~B}(\mathrm{NF}-\kappa \mathrm{B})$ pathway thought to be responsible for resistance to treatment in this subset of chronic lymphocytic leukemia patients ${ }^{30-34}$ (Figure 1 and Tables 1-3).

BIRC3 mutations are present in $4 \%$ of newly diagnosed chronic lymphocytic leukemia patients and are in up to $25 \%$ of patients with relapsed and fludarabine-refractory chronic lymphocytic leukemia. ${ }^{29}$ These mutations are also associated with other adverse prognostic factors that predict chemo-refractoriness and poorer prognosis $9,29,31$ (Figure 1 and Tables 1-3). As a result, a recent review classified patients with chronic lymphocytic leukemia containing BIRC3 aberrations as being very high risk, with recommended therapeutic strategies including p53-independent drugs, BTK inhibitors, and allogeneic stem cell transplantation. ${ }^{35}$

MYD88. MYD88 mutations have been detected in 1.5-4\% of chronic lymphocytic leukemia cases, identifying a population of patients with favorable outcome: ${ }^{36-38}$ diagnosis at a younger age ( $\leq 50$ years), association with low expression of CD38 and ZAP-70 , and a higher frequency of mutated $I G H V .^{36,39}$ MYD88 mutations in chronic lymphocytic leukemia patients are associated with a good prognosis and confer an OS similar to an age- and gender-matched population of patients without chronic lymphocytic leukemia ${ }^{36}$ (Table 1). 


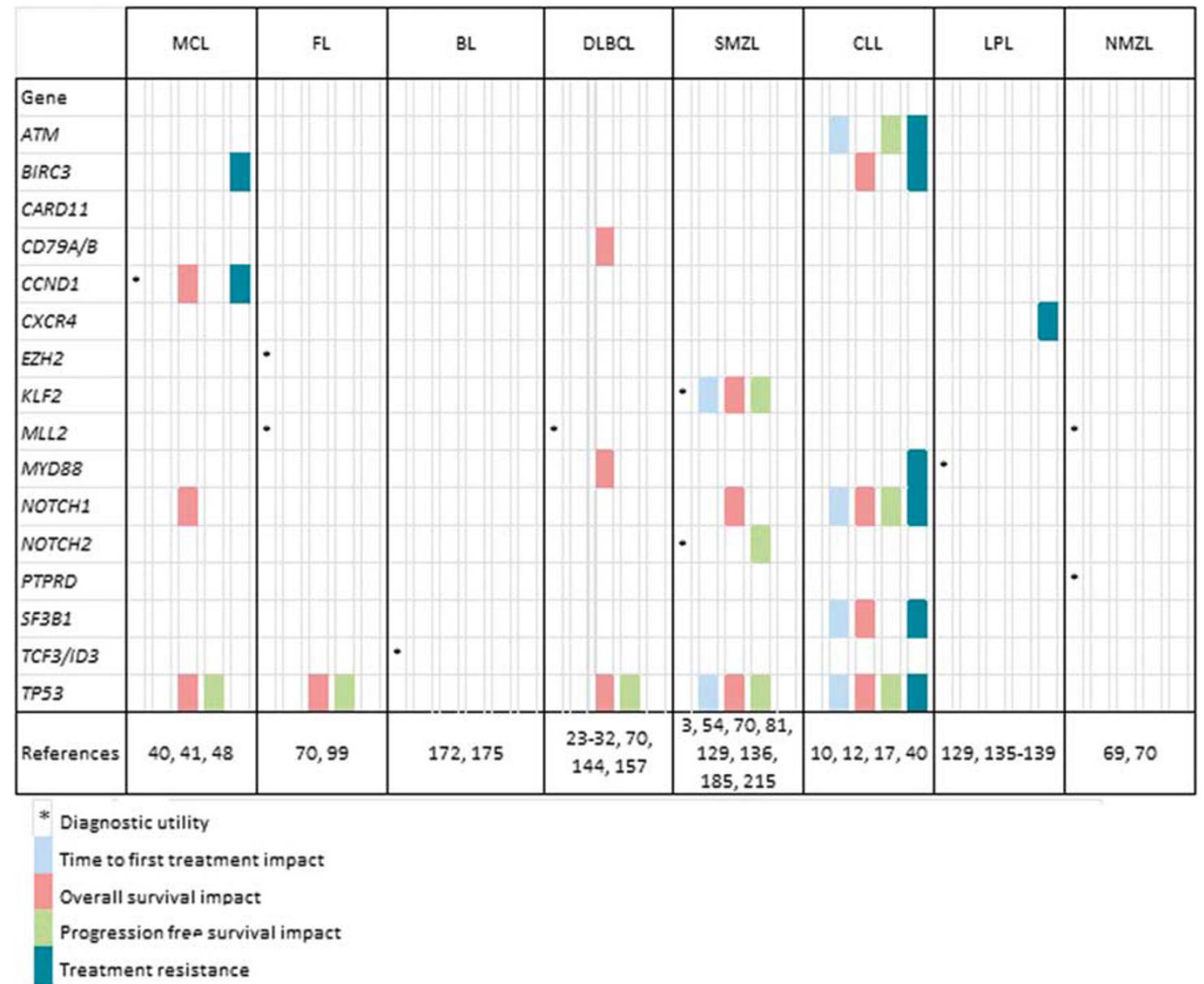

Figure 1 Clinical impact of recurrent driver alterations in mature B-cell non-Hodgkin lymphomas. BL: Burkitt lymphoma; CLL: chronic lymphocytic leukemia; DLBCL: diffuse large B-cell lymphoma; FL: follicular lymphoma; LPL: lymphoplasmacytic lymphoma; MCL: mantle cell lymphoma; NMZL: nodal marginal zone lymphoma; SMZL: splenic marginal zone lymphoma.

NOTCH1 mutations. NOTCH1 mutations in chronic lymphocytic leukemia are mainly represented by frameshift or nonsense events that cluster within exon 34 , including the highly recurrent c.7544_7545delCT deletion (80-95\% of all mutations), that disrupt the C-terminal PEST domain of the protein. NOTCH1 mutations cause impaired degradation of protein and result in sustained NOTCH signaling ${ }^{40,41}$ with consequent deregulation of cell metabolism and cell-cycle progression ${ }^{39}$ (Figures 2 and 3). Recently, mutations in the $3^{\prime}$ untranslated region (UTR), predicted to result in alternative splicing, have been associated with an adverse prognosis in chronic lymphocytic leukemia patients. ${ }^{38}$

NOTCH1 mutations are present in $5-10 \%$ of newly diagnosed chronic lymphocytic leukemia cases and are enriched in chronic lymphocytic leukemia patients with evidence of progressive disease (15-20\%). ${ }^{13-15}$ NOTCH1 mutations predict a shorter overall survival (median overall survival 54.8 vs 74.6 months $)$, progression-free survival $(2.0 \mathrm{Vs}$ 26.4 months), ${ }^{14}$ and time to treatment ${ }^{17}$ (Figure 1 and Table 1). NOTCH1 mutations also have been identified as a predictive marker for patients who are less likely to respond to the addition of rituximab to fludarabine-based therapeutic regimens. ${ }^{17}$ Patients with chronic lymphocytic leukemia that carry NOTCH1 mutations have an increased risk of transformation to DLBCL, also known as Richter syndrome. ${ }^{13,39,42}$ In up to $90 \%$ of cases of Richter syndrome NOTCH1 mutations have been identified $^{19}$ (Figure 1 and Tables 1-3). Targeted therapy using NOTCH signaling inhibitors $(\Upsilon$-secretase inhibitors) ${ }^{43}$ is available for chronic lymphocytic leukemia patients, but further studies are needed to confirm the utility of these drugs in this clinical setting.

Splicing factor $3 b$, subunit 1 . Mutations in splicing factor $3 \mathrm{~b}$, subunit 1 (SF3B1) have been identified in $4-12 \%$ of chronic lymphocytic leukemia patients, with a higher frequency $(17-24 \%)$ at the time of disease progression ${ }^{20,44}$ (Tables 1-3). SF3B1 is located on chromosome 2q33.1 and encodes a critical component of the RNA splicing machinery that ensures successful transcription and functional 


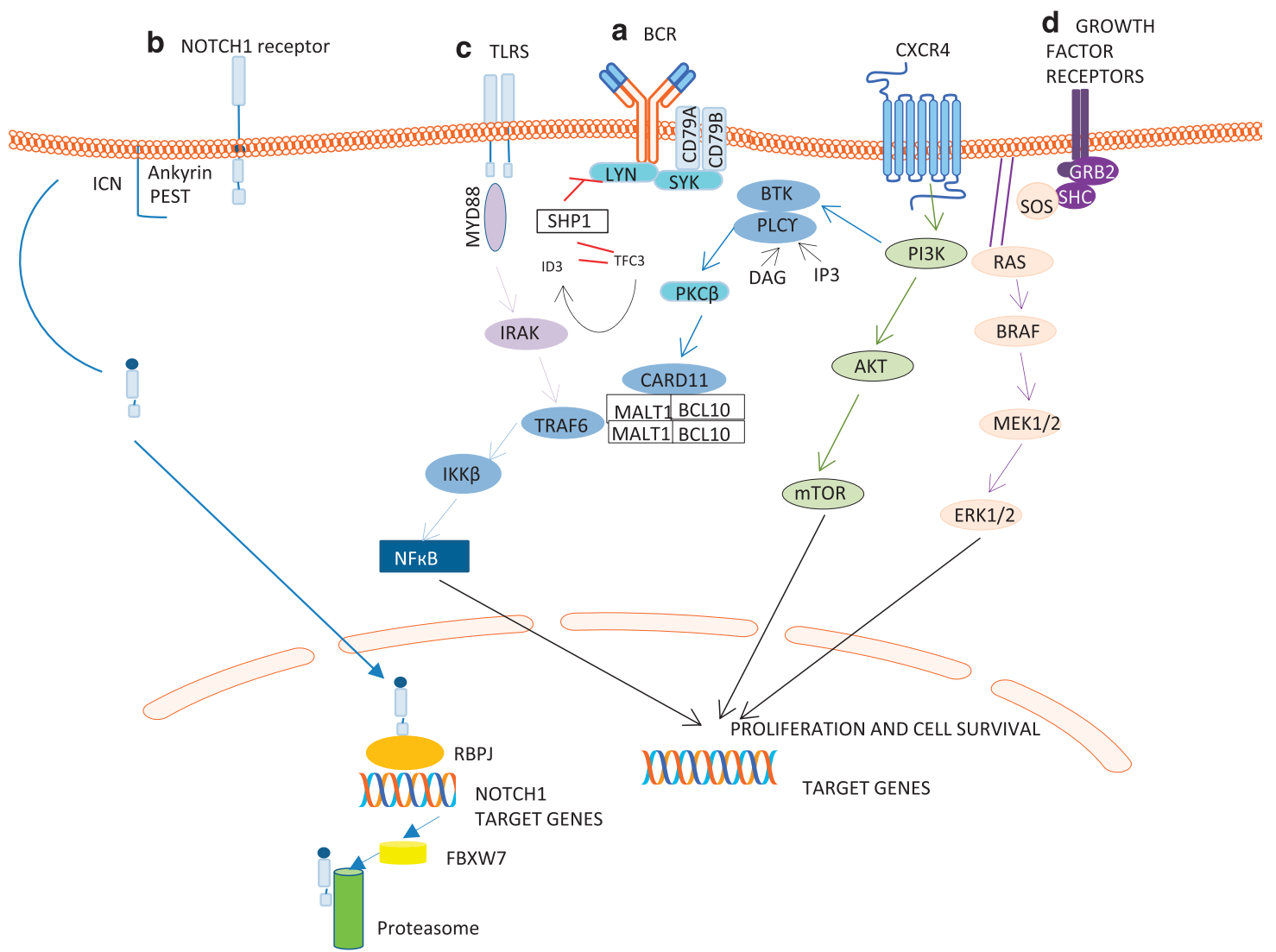

Figure 2 Schematic representation of the key pathways activated in B-cell mature neoplasms. (a) BCR signaling pathway. The BCR is composed of a membrane immunoglobulin (IgM) bound to CD79A and CD79B. CD79A is a transmembrane protein with a cytoplasmic domain that contains multiple phosphorylation sites including a conserved dual tyrosine binding motif, termed immunotyrosine-based activation motif (ITAM). CD79A has several cysteine residues, one of which forms covalent bonds with CD79b. Association of the CD79A/B heterodimer with the immunoglobulin heavy chain is required for surface expression of the BCR. BCR antigen binding induces the recruitment of Src family kinases (SYK and LYN) and signaling initiation through the phosphorylation of the ITAM domains. Subsequently, the Bruton's tyrosine kinase (BTK), phospholipase Cr2 (PLCr2), and phosphoinositide 3 kinase (PI3K) are activated. BTK leads to phosphorylation of PLCr2, promoting the production of diacylglycerol (DAG) and IP3, which IP3 activate protein kinase $\mathrm{C} \beta(\mathrm{PKC} \beta)$, leading to CARD11 phosphorylation, and the recruitment of the molecules MALT1 and BCL10 necessary for CBM multiprotein complex composition. This finally leads to activation of the IKK $\beta$ kinase and NF- $k B$ signaling initiation. Mutations affecting CD79A and CD79B ITAM domains have been described in enhancing BCR signaling through a decrease of BCR internalization after its ligand activation. CARD11 mutations also sustain NF- $k$ B activation promoting spontaneous multimerization of the complex, and NF- $\kappa \mathrm{B}$ signaling pathway activation in a BCR-independent manner. TCF3 promotes BCR signaling by transactivating the immunoglobulin heavy- and light-chain genes, thereby increasing surface BCR expression, and by repressing the PTPN6 gene, which encodes the BCR signaling inhibitor SHP-1. (b) NOTCH1 signaling pathway. NOTCH1 signaling is initiated when a ligand from the Jagged or Delta families binds the receptor and induces a cascade of proteolytic processes that results in the release and nuclear translocation of the NOTCH1 intracellular domain (NCID). This, in conjunction with the transcription factor CBF1/RBP-Jk, leads to the activation or repression of its target genes. NOTCH1 truncating mutations remove sites of recognition for the E3 ligase FBW7 that targets NOTCH1 for ubiquitin-mediated proteasomal degradation. Thus, NOTCH1 mutations lead to an impairment of the degradation of NOTCH1 protein and stabilization of its active form. NOTCH1 signaling pathway activation leads to deregulation of several pathways, including those controlling cell metabolism and cell-cycle progression. (c) TOLL-like receptor pathway. Upon ligand binding, Toll-like receptors (TLR) aggregate and initiate intracellular signaling by engaging various cytoplasmic adaptors, including MYD88. The MYD88 gene encodes for an adapter protein that acts as a signal transducer in the IL-1, IL-18, and Toll-like receptor signaling pathways, as part of the innate immune response. The MYD88 protein consists of an N-terminal death domain, a linker region, and a C-terminal TIR domain, which may mediate contact with TLR TIR domains upon signaling activation. MYD88 mutations results in uncontrolled formation of the MYD88/IRAK complex, recruitment of TRAF6, constitutive phosphorylation of TAK1, and NF- $\kappa$ B signaling activation. (d) RAS/MAPK/ERK/pathway: the BRAF protein is a member of the serine-threonine kinase RAF family (comprising RAF-1/CRAF, ARAF, and BRAF). Under physiological conditions, the ligand-receptor binding activates that pathway, triggering the recruitment of the adaptor molecules Grb2 to the inner part of the cell membrane and its binding to the guanine nucleotide-exchange factor SOS. Activated SOS displaces guanosine diphosphate from RAS, promoting the formation of guanosine triphosphate-RAS, which recruits BRAF to the cell membrane where it is phosphorylated. In its active form, phosphorylated BRAF can form BRAF-CRAF heterodimers that in turn lead to activation of MEK1 and MEK2, that phosphorylate extracellular signal-regulated kinases 1 and 2 (ERK1 and ERK2). Phosphorylated ERK1 and ERK2 are translocated to the nucleus, where they activate different transcription factors of target genes that promote cell-cycle progression and survival. BRAF mutants can phosphorylate ERK as monomers and in a RAS and ligand-independent manner. Thus, BRAFV600E in Hairy cell leukemia constitutively activates the RAF-MEK-ERK pathway leading to enhanced survival of the neoplastic cells. 


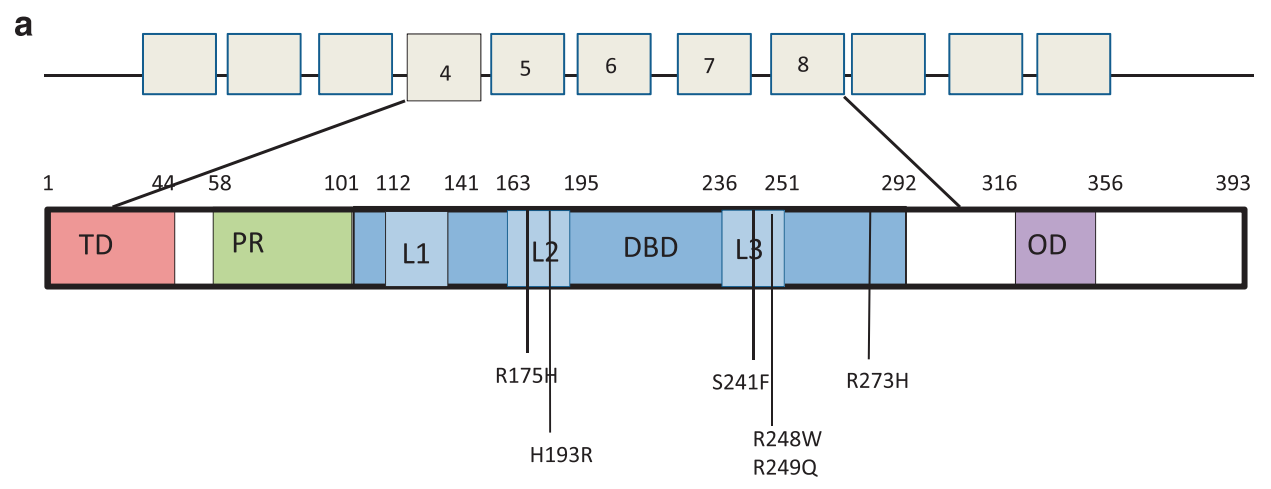

b

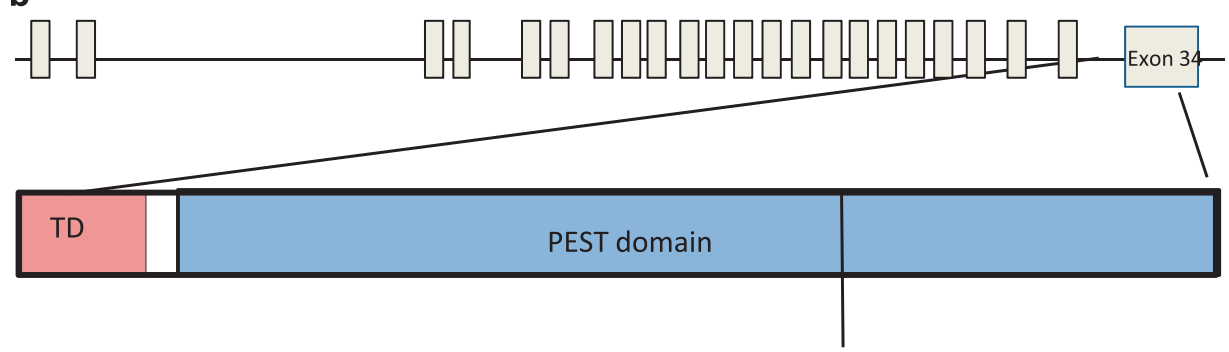

NOTCH1

P2514fs*4 (41)

C

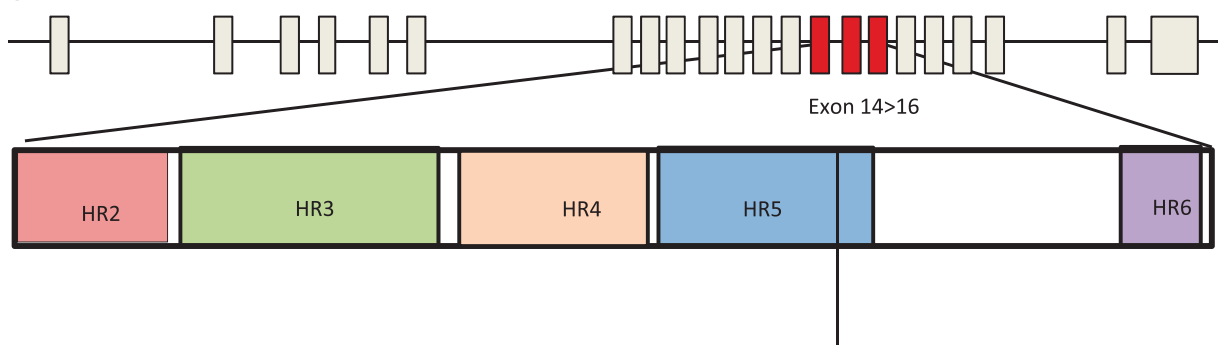

SF3B1

700>K/E (37)

Figure 3 Schematic representation of key hotspot mutations in driver genes in chronic lymphocytic leukemia. (a) Schematic representation of the TP53 and main hotspot mutations in chronic lymphocytic leukemia (CLL)/small lymphocytic lymphoma (SLL). The p53 protein is divided into five domains: an RNA polymerase transactivating domain, a proline-rich domain, a DNA-binding domain, a tetramerization domain, and a carboxy-terminal regulatory domain. TP53 DNA-binding domain (DBD) is divided into three loops: L1 (codons 112-141), L2 (codons 163-195), and L3 (codons 236-251), and two loop-sheet-helix regions (codons 119- 135; 272-287). TP53 inactivating mutations usually cluster in the DNA-binding domain DBD (encoded by exons 4-8). The main hotspot mutations in CLL are R175H, H193, S241, R248W, R249Q, R273H. (b) Schematic representation of the NOTCH1 protein and main hotspot mutation in CLL. The two base-pair deletion in codon 2514 (c.7541_7542delCT) in exon 34 accounts for 80-95\% of all NOTCH1 mutations in CLL. This frameshift mutation disrupts the C-terminal PEST domain of the protein leading to the generation of a more active protein, impairing NOTCH1 proteasomal degradation by removing sites of recognition for the E3 ligase FBW7, necessary for NOTCH1 for ubiquitin-mediated degradation. (c) Schematic representation of SF3B1. Somatically acquired mutations in SF3B1 generally represent missense nucleotide changes, clustered in selected HEAT repeats of the SF3B1 protein, recurrently targeted three hotspots (codons 662, 666, and 700).

diversity of protein species using alternative spicing. Mutations in SF3B1 are somatically acquired, are generally represented by missense nucleotide changes, and are clustered in selected tandem repeat protein motifs (known as HEAT repeats) of the $155 \mathrm{kDa}$ SF3B1 protein. There are three mutation hotspots at codons 662, 666, and 700 (Figure 3). SF3B1 mutations are associated with adverse biological parameters, ${ }^{20}$ and correlate with shorter time to treatment (3.8 vs 8.0 years), 5-year overall survival $(64.7 \%$ vs $86.7 \%)$, fludarabine-refractory disease, and poorer OS. ${ }^{13,18,45}$ SF3B1 mutations are also associated with del(11q) $(20.3 \%$ vs $7.5 \%)$ and are less frequently present in chronic lymphocytic leukemia associated with $\operatorname{del}(13 \mathrm{q})(7.5 \%$ vs $11.2 \%)$, contributing to the prognostic stratification of these cytogenetic subgroups of patients ${ }^{20}$ (Figure 1 and Tables 1-3).

Tumor-suppressor p53. A deleterious tumorsuppressor p53 (TP53) alteration is the most informative predictor of poor outcome in chronic lymphocytic 
leukemia patients. TP53 mutations predict for shorter overall survival, progression-free survival, time to first treatment, and are associated with a poorer response or refractoriness to fludarabinecontaining regimens. ${ }^{9}$ TP53 codons 248 and 273 represent the most common hotspots in chronic lymphocytic leukemia and are affected by missense $(73.9 \%)$ and nonsense $(4.1 \%)$ mutations ${ }^{46}$ (Table 1 and Figure 3). TP53 mutations have been found in $4-10 \%$ of patients with untreated chronic lymphocytic leukemia, ${ }^{47,48}$ and are frequently present in association with NOTCH1 and SF3B1 mutations (16.1\% and $14 \%$, respectively). ${ }^{49}$ TP53 mutations are enriched in IGHV unmutated cases, and are detected with a significantly lower frequency in chronic lymphocytic leukemia cases carrying del (11q) or trisomy $12 .{ }^{17}$ TP53 mutations and deletions of 17 p13 are closely associated. Deletion of $17 \mathrm{p}$ is found in $4-9 \%$ of chronic lymphocytic leukemia patients at diagnosis or at initiation of first treatment, ${ }^{47,50-52}$ and always includes band $17 \mathrm{p} 13$, where the tumor-suppressor gene TP53 is located. In the study originally performed by Rossi et al, ${ }^{53}$ the median overall survival for patients with TP53 mutations was 79.6 months and 5-year overall survival was $66.2 \%$ compared with $85.2 \%$ in patients without TP53 mutations. Five-year overall survival for patients with del17p13 was 65.8\% (median, overall survival 104.2 months) compared with $86.9 \%$ for patients without del17p13. Furthermore, TP53 inactivation is associated with progression and transformation to aggressive DLBCL, being present in $40 \%$ of patients who develop Richter syndrome. It also represents an independent predictor of overall survival after Richter syndrome transformation ${ }^{18,19}$ (Figure 1 and Tables 1-3).

TP53 mutations predict refractoriness to chemotherapy independently of concomitant del17p13. Median time to chemo-refractoriness in the cohort studied by Rossi et $a l^{53}$ for patients treated with fludarabine-based regimens was 6.3 months in TP53 mutated patients versus 72.7 months for patients without TP53 mutations. The results of the CLL8 trial of a large series of untreated chronic lymphocytic leukemia patients, which evaluated firstline therapy with fludarabine and cyclophosphamide versus fludarabine and cyclophosphamide with rituximab among patients with untreated disease $^{53}$ confirmed that $17 \mathrm{p} 13$ deletions and TP53 mutations are associated with treatment refractoriness, and represent independent adverse markers for fludarabine-based treatments, for all efficacy end points $^{49}$ (Figure 1).

Currently, the National Cancer Center Network (NCCN) guidelines and the European Research Initiative on Research in chronic lymphocytic leukemia (ERIC) guidelines recommend assessment for TP53 abnormalities in all de novo chronic lymphocytic leukemia patients, in outside-clinical trial patients who would be eligible to an allogeneic stem cell transplantation or other intensive therapies, as well as in previously treated patients with wildtype TP53 at the initial diagnosis if further therapy is required. ${ }^{4,54}$ The last update of the NCCN guidelines suggested ibrutinib and idelalisib as therapeutic choices in patients with de novo or relapsed chronic lymphocytic leukemia with TP53 mutations or del (17p). ${ }^{4}$ The ERIC recommendations ${ }^{54}$ indicate that patients with TP53 mutations may be considered for allogeneic stem cell transplantation in first remission. Alemtuzumab-based regimens obtain a high proportion of complete responses, but with short duration. It is encouraged that these patients be included in new clinical trials with novel therapeutic agents.

BTK and PLCG2 mutations are mechanisms of resistance to Ibrutinib treatment. Bruton tyrosine kinase $(B T K)$ is transcriptionally upregulated and constitutively active in chronic lymphocytic leukemia. Ibrutinib, a BTK inhibitor, irreversibly binds BTK at the C481 residue, inactivates the kinase, and induces chronic lymphocytic leukemia cells to undergo apoptosis through inhibition of the BCR signaling pathway. The NCCN guidelines ${ }^{4}$ suggest treatment with ibrutinib in patients with relapsed chronic lymphocytic leukemia, as ibrutinib therapy is associated with partial or complete responses in $71 \%$ of patients. ${ }^{55}$ Resistance to ibrutinib often involves a mutation of a cysteine residue where ibrutinib binding occurs. Functional analysis has shown that the C481S mutation of BTK results in a protein that is only reversibly inhibited by ibrutinib. The S707Y mutation in PLCG2, located immediately downstream to BTK in the BCR signaling pathway, has a gain-of-function effect owing to disruption of an autoinhibitory SH2 domain. The R665W and L845F mutations in PLCG2 are both potentially gainof-function mutations that lead to autonomous B-cell-receptor activity ${ }^{56}$ (Table 3).

Subclonal mutations in chronic lymphocytic leukemia. In addition to specific clonal aberrations, many subclonal aberrations have been identified in chronic lymphocytic leukemia cases. Several studies show that subclonal mutations are associated with a poorer prognosis because clonal evolution is a key feature of cancer progression and relapse. Tumor subclones can exhibit different somatic mutations in the same gene and can expand over time. Jethwa et $a l^{57}$ demonstrated the presence of convergence in chronic lymphocytic leukemia, and also brought evidence that most mutations in chronic lymphocytic leukemia are subclonal and found in $68 \%$ of the cases. Whole-exome studies had previously shown the presence of subclonal driver mutations, such as TP53 and SF3B1, expanding over time and representing an independent risk factor for rapid disease progression. ${ }^{58}$ Previously unrecognized chronic lymphocytic leukemia driver genes, such as RPS15 and IKZF3, and new potentially targetable 
pathways also have been identified in subclonal populations. Thus, early detection, monitoring and quantification of subclones in chronic lymphocytic leukemia are clinically relevant.

\section{Splenic Marginal Zone Lymphoma}

Splenic marginal zone lymphoma is an indolent small B-cell lymphoma involving the spleen, splenic hiliar and abdominal lymph nodes, and bone marrow that exhibits a striking clinical variability. Ten-year survival varies from 42 to $95 \%$ in different studies, ${ }^{59-61}$ and adverse clinical prognostic factors are related to high tumor burden and poor performance status. Whole-exome sequencing of splenic marginal zone lymphoma cases has shown mutations in genes involved in marginal zone differentiation (NOTCH2 in $25 \%, K L F 2$ in $21 \%$ and others). ${ }^{36,40,41,62,63}$ Specific genetic and molecular features, such as deletion of $7 \mathrm{q}$, unmutated IGHV genes, NOTCH2 and KLF2 mutations, and TP53 inactivation $(16 \%),{ }^{64}$ have been associated with histological signs of progression in splenic marginal zone lymphoma ${ }^{65-67}$ (Figure 1 and Table 2). Additional recurrently mutated genes have been described: MAP3K14 (15\%), MYD88 (13\%), BIRC3 (10\%), IKBKB (8\%), TNFAIP1 (7\%), ARID1A (6\%), TRAF3 (5\%), and KTM2D/MLL2 (4.7\%).

BIRC3 and TRAF3. BIRC3 and TRAF3 inactivating mutations (frameshift or nonsense substitutions) have been described in up to $10 \%$ and $5 \%$ of splenic marginal zone lymphoma and extranodal MZL, respectively, ${ }^{29}$ leading to non-canonical (BIRC3, TRAF3, MAP3K14) NF- $\kappa$ B pathway constitutive activation. ${ }^{29,34,41}$ Inactivating mutations in TRAF3 lead to elimination of the C-terminal MATH domain of the protein that provides a docking site for MAP3K14 and is required for MAP3K14 recruitment to BIRC3 degradation. Thus, TRAF3 and BIRC3 mutations cause MAP3K14 stabilization in the cytoplasm and constitutive activation of the non-canonical $\mathrm{NF}-\kappa \mathrm{B}$ signaling pathway ${ }^{29}$ (Figure 2).

KLF2. Truncating KLF2 mutations, including frameshift, nonsense substitutions, and splice-site mutations, have been identified in up to $20 \%$ of splenic marginal zone lymphoma cases. The aberrant transcripts retain intronic sequences and lose their coding potential, ${ }^{62}$ thereby disrupting the entire protein or removing the zinc-finger domains of the nuclear localization signal. ${ }^{68}$ KLF2 mutations that cluster in the $\mathrm{C} 2 \mathrm{H} 2$ domain ( $\mathrm{C}$ terminus) are an independent poor prognostic factor in splenic marginal zone lymphoma patients, and are found in association with $\operatorname{del}(7 q)$ (53\% with KLF2 mutation vs $11 \%$ without mutation), unmutated IGHV genes $(50 \%$ Vs $7 \%)$, and other gene mutations including NOTCH2, TNFAIP3, and ARID1A. KLF2 mutations confer a higher risk of patients requiring treatment, including splenectomy, and predict for shorter time to treatment, higher risk of histological transformation, and shorter overall survival ${ }^{64}$ (Figure 1 and Table 2).

NOTCH1/2 and TP53. Splenic marginal zone lymphoma cases carry alterations of genes belonging to the NOTCH pathway in $30-40 \%$ of cases. ${ }^{41}$ The NOTCH2 gene, located on chromosome 1p13-p11, is one of the most frequently mutated genes in splenic marginal zone lymphoma (20-25\%), and predicts for a worse outcome. ${ }^{40,41}$ NOTCH2 mutations in splenic marginal zone lymphoma have been associated with increased risk of histological transformation, shorter relapse-free survival, and shorter time to histological transformation and/or death (32.6 vs 107.2 months in NOTCH2 wild-type patients) ${ }^{40}$ (Figure 1 and Table 2). NOTCH1 also is mutated in $5 \%$ of splenic marginal zone lymphoma. ${ }^{41}$

TP53 mutations have been identified in 16\% of splenic marginal zone lymphoma cases, representing an independent prognostic factor for shorter time to first treatment, progression-free survival, and overall survival $^{64}$ (Figure 1 and Tables 3 and 4).

Somatic hypermutation of IGH and VH family utilization. About $50 \%$ of splenic marginal zone lymphoma cases exhibit somatic hypermutations of the $I G H V$ genes. The absence of somatic mutations in the IGHV genes has been associated with histological signs of progression. ${ }^{65-67}$ Bias in VH1-2 usage has been found in mutated and unmutated cases, suggesting that splenic marginal zone lymphoma is derived from a highly selected B-cell population. In one study, utilization of three $I G H V$ genes accounted for about $50 \%$ of cases: IGHV1-2, 24.9\%; IGHV4-34, $12.8 \%$; and IGHV3-23, 8.1\%. ${ }^{69}$

\section{Hairy Cell Leukemia and Hairy Cell Leukemia Variant}

$B R A F$. A recurrent mutation involving the protooncogene $B R A F$, located at chromosome $7 \mathrm{p} 24$, was recognized in 2011 as a causal genetic event in hairy cell leukemia. To date, $B R A F$ mutations have been detected in $>97 \%$ of hairy cell leukemia patients, ${ }^{70-72}$ and $B R A F$ mutation testing is described as essential in the 2016 NCCN guidelines 2016. ${ }^{4,5}$ BRAFV600E is a point mutation which results in substitution of thymine for adenine at position 1799 on exon 15 and a change of amino acid 600 from valine (V) to glutamate (E). The overall effect is constitutive activation of the RAS-RAFMEK-ERK signaling pathway (Figure 2). The availability of BRAF and MEK inhibitors, originally developed for the treatment of $B R A F$-mutated metastatic melanoma, ${ }^{73}$ offers a new therapeutic opportunity for hairy cell leukemia patients who become refractory to purine analog treatment and/or 
Table 4 Clinical significance of the main driver mutations in mature B-cell lymphoid neoplasms

\begin{tabular}{|c|c|c|c|c|c|}
\hline $\begin{array}{l}\text { Mutated } \\
\text { gene }\end{array}$ & $\begin{array}{l}\text { Chromosome } \\
\text { location }\end{array}$ & Location/typical mutation & Disease & Frequency & Clinical significance \\
\hline \multirow[t]{5}{*}{ TP53 } & \multirow[t]{5}{*}{$17 \mathrm{p} 13.1$} & \multirow[t]{5}{*}{$\begin{array}{l}\text { Non-synonymous (missense, nonsense, and } \\
\text { splice-site mutations) in exons } 4-8 \text { corresponding } \\
\text { to DBD (Loop 1, 3, and LSH, codons } 272 \text { to 287) }\end{array}$} & DLBCL & $21 \%$ & $\begin{array}{l}\text { Younger age at diagnosis, high serum LDH, bulky tumors, } \\
\text { and high IPI risk group. } \\
\text { Shorter median 5-year survival in DLBCL patients } \\
\text { Stratification of DLBCL-GCB in two different subgroups } \\
\text { upon TP53 mutational status, predicting for worse outcome } \\
\text { in the TP53 mutated subgroup. }\end{array}$ \\
\hline & & & SMZL & $16 \%$ & Shorter TTT, EFS, and OS \\
\hline & & & MCL & $7-20 \%$ & Decreased OS. \\
\hline & & & & & $\begin{array}{l}\text { Controversial association with the more aggressive blastoid } \\
\text { variant. }\end{array}$ \\
\hline & & & FL & $6 \%$ & $\begin{array}{l}\text { Presentation at elderly older ages in patients with higher IPI } \\
\text { Poorer OS and PFS. }\end{array}$ \\
\hline \multirow[t]{3}{*}{$K L F 2$} & \multirow[t]{3}{*}{ 19p13.11 } & \multirow[t]{3}{*}{ Frameshift mutations affecting $\mathrm{C} 2 \mathrm{H} 2$ domain } & SMZL & $12 \%$ & $\begin{array}{l}\text { Association with del(7q), unmutated IGHV, and NOTCH2, } \\
\text { TNFAIP3, and ARID1A. }\end{array}$ \\
\hline & & & & & Higher risk of transformation (11\%). \\
\hline & & & & & $\begin{array}{l}\text { Shorter TTT and OS. Higher risk of receiving treatment } \\
\text { (including splenectomy). }\end{array}$ \\
\hline BIRC3 & $11 q 22$ & Deletions, frameshifts, or nonsense mutations & MCL & $15 \%$ & Ibrutinib insensitivity in cell lines. \\
\hline NOTCH1 & 9q34.3 & $\begin{array}{l}\text { Frameshift or nonsense events clustering within } \\
\text { exon 34. Highly recurrent c. } 7544 \text { 7545delCTdeletion }\end{array}$ & MCL & $12 \%$ & Decreased OS; no correlation with progression. \\
\hline \multirow[t]{4}{*}{ NOTCH2 } & \multirow[t]{4}{*}{ 1p13-p11 } & \multirow{4}{*}{$\begin{array}{l}\text { Frameshift or nonsense events clustering within } \\
\text { exon } 34 \\
\text { Highly recurrent c. } 7544 \text { 7545delCTdeletion }\end{array}$} & \multirow[t]{4}{*}{ SMZL } & \multirow[t]{4}{*}{$20-25 \%$} & Histological transformation \\
\hline & & & & & Shorter relapse-free survival \\
\hline & & & & & Shorter time to adverse outcome \\
\hline & & & & & Marginal zone differentiation \\
\hline \multirow[t]{2}{*}{ CCND1 } & \multirow[t]{2}{*}{$11 \mathrm{q} 13.3$} & \multirow[t]{2}{*}{ Exon 1 point mutations (E36K, Y44D, and C47S) } & \multirow[t]{2}{*}{ MCL } & \multirow[t]{2}{*}{$18-35 \%$} & $\begin{array}{l}\text { Higher tumor proliferation } \\
\text { Shorter overall survival }\end{array}$ \\
\hline & & & & & Ibrutinib resistance \\
\hline$C D 79 A / B$ & $19 q 13.2$ & Non-synonymous missense substitutions & $\begin{array}{l}\text { DLBCL- } \\
\text { ABC }\end{array}$ & $20 \%$ & $\begin{array}{l}\text { Worse outcome associated with the activated B-cell } \\
\text { phenotype }\end{array}$ \\
\hline \multirow[t]{4}{*}{ MYD88 } & \multirow[t]{4}{*}{$3 \mathrm{p} 22$} & Single-nucleotide L265P & $\mathrm{LPL} / \mathrm{WM}$ & $67-100 \%$ & Diagnostic biomarker for LPL/WM \\
\hline & & \multirow[t]{3}{*}{ Missense substitution } & \multirow[t]{3}{*}{ DLBCL } & $12-24 \%$ & Association with adverse clinical presentation and worse \\
\hline & & & & DLBCL-ABC & Presentation at older ages, more advanced stage, with \\
\hline & & & & $10 \%$ DLBCL-GCB & $\begin{array}{l}\text { frequent extranodal involvement, with higher IPI scores } \\
\text { Shorter OS }\end{array}$ \\
\hline \multirow[t]{5}{*}{ CXCR4 } & \multirow[t]{5}{*}{$2 q 22}$. & Nonsense and frameshift mutations affecting the & LPL & $98 \%$ of MYD88 & Higher disease activity higher disease burden, higher serum \\
\hline & & \multirow{4}{*}{ C-terminal domain } & WM & LPL-mutants & IgM levels, a higher extent of bone marrow infiltration and \\
\hline & & & & $27 \%$ of $\mathrm{WM}$ & lower levels of leukocytes, hemoglobin and platelet counts, \\
\hline & & & & & $\begin{array}{l}\text { and a higher incidence of lymphadenopathy } \\
\text { No impact on OS }\end{array}$ \\
\hline & & & & & BTK inhibitors-resistance \\
\hline
\end{tabular}

Abbreviations: ATM: Ataxia-telangiectasia mutated gene; BIRC3: Baculovavial IAP repeat containing 3 gene; CLL: chronic lymphocytic leukemia; DBD: DNA-binding domain; DLBCL-GCB: germinal center B cell-like DLBCL; FL: follicular lymphoma; IGHV, immunoglobulin heavy-chain variable region genes; IPI: International Prognostic Index score; LPL: lymphoplasmacytic lymphoma; LSH (L1)-sheet-helix (LSH) motif; MCL: mantle cell lymphoma; OS: overall survival; PFS: progression-free survival; RS: Rychter syndrome; SMZL: splenic marginal zone lymphoma; TTT: time to first treatment; WM: Waldestrom macroglobulinemia. 
anti-CD20 monoclonal antibody (rituximab), ${ }^{74}$ as mentioned in the NCCN guidelines update. ${ }^{4}$

Most $(>85 \%)$ of hairy cell leukemia cases have $V H$ genes with somatic hypermutation, indicative of a post-germinal center stage of maturation. Different studies have shown that hairy cell leukemia cases with unmutated $I G H$ genes predict for shorter patient survival. ${ }^{75}$ Thus, molecular analysis to detect IGHV mutational status is considered useful under certain circumstances in the NCCN guidelines. ${ }^{4}$

MAP2K1. Hairy cell leukemia variant bears morphologic resemblance to hairy cell leukemia, but is no longer considered to be closely related. Distinguishing hairy cell leukemia from hairy cell leukemia variant is important because patients with hairy cell leukemia variant are often resistant to conventional hairy cell leukemia therapy. The neoplastic cells of hairy cell leukemia variant have nucleoli, unlike classical hairy cell leukemia, and are usually negative for CD25, CD123, and CD200. There is no distinct chromosomal abnormality in hairy cell leukemia variant, but del(17p13) and TP53 mutations are frequent. Mutations of the IGHV, particularly involving the $\mathrm{VH} 4-34$, are observed in twothirds of cases and are associated with higher disease burden at diagnosis, poor response to single agent cladribine, and shorter overall survival. ${ }^{76}$ Wholeexome sequencing has documented mutations of $M A P 2 K 1$ in $48 \%$ of hairy cell leukemia-variant cases and classical hairy cell leukemia with IGHV4-34 family usage in one study, ${ }^{77}$ whereas $B R A F$ mutations have not been shown in hairy cell leukemia variant to date. ${ }^{70} \mathrm{MAP} 2 \mathrm{~K} 1$ encodes the dual specificity kinase MEK1, which is a direct effector of BRAF and directly upstream of ERK1/2 in the MAPK pathway, inducing an increase in basal enzymatic activity and cell proliferation ${ }^{77}$ (Figure 2).

\section{Lymphoplasmacytic Lymphoma/Waldenstrom Macroglobulinemia}

Lymphoplasmacytic lymphoma is defined as a B-cell neoplasm composed of lymphocytes, plasmacytoid lymphocytes, and plasma cells that does not meet criteria for other types of small B-cell lymphoma. Waldenstrom macroglobulinemia is defined as lymphoplasmacytic lymphoma involving the bone marrow and associated with a serum monoclonal IgM paraprotein of any level. About 95\% of all cases of lymphoplasmacytic lymphoma are also Waldenström macroglobulinemia and therefore the molecular data regarding lymphoplasmacytic lymphoma are derived primarily from the study of Waldenström macroglobulinemia cases.

MYD88. Somatic mutations affecting the myeloid differentiation primary response 88 gene (MYD88), located on chromosome 3p22, were described initially by $\mathrm{Ngo}$ et $a l^{78}$ in 2011 and the reported frequency of mutation in Waldenström macroglobulinemia ranges from $67 \%$ to nearly $100 \% .^{79}$ MYD88 L265P mutations are also common $^{79-82}$ in IgM, monoclonal gammopathy of undetermined significance (45-87\%), suggesting that this mutation may be an early oncogenic event. Relatively few cases of the non-Waldenström macroglobulinemia type of lymphoplasmacytic lymphoma have been assessed and MYD88 mutations have been shown in a subset of cases, but less frequently than in Waldenström macroglobulinemia. Mutations result in an L265P missense substitution, affect the C-terminal TIR domain of the proteinm, and result in uncontrolled formation of the MYD88/IRAK complex, recruitment of TRAF6, constitutive phosphorylation of TAK1, and activation of NF- $\kappa \mathrm{B}$ signaling ${ }^{78,79,83}$ (Figure 2). The presence of MYD88 mutation has prognostic significance as patients with mutation respond better to ibrutinib than patients who are wild type. ${ }^{5}$ MYD88 L265P mutations have been proposed as a diagnostic biomarker, helpful in the differential diagnosis of Waldenström macroglobulinemia from other overlapping B-cell neoplasms such as MZLs, ${ }^{84,85}$ as stated by the NCCN guidelines ${ }^{4}$ (Figure 1 and Tables 3 and 4). However, MYD88 L265P is not specific as this mutation has been identified in $4-13 \%$ of splenic marginal zone lymphoma, $7-9 \%$ of MALT lymphoma ${ }^{78,86} 1.5-4 \%$ of chronic lymphocytic leukemia, 20,39 and in DLBCL, particularly activated B-cell-like DLBCL (30-40\%) and DLBCL of the central nervous system and testis $(70-75 \%)$. The last update of the NCCN guidelines included MYD88 L265P testing of the bone marrow as being essential (instead of useful) in lymphoplasmacytic lymphoma/Waldenström macroglobulinemia diagnosis. Furthermore, NCCN guidelines recommend testing for non-L265P MYD88 mutations in patients with Waldenström macroglobulinemia in whom MYD88 L265P mutation is not detected in an adequate sample. ${ }^{5}$

CXCR4. The chemokine (C-X-C motif) receptor type 4 (CXCR4) is the second most common gene mutated in Waldenström macroglobulinemia, in about $30 \%$ of cases, and the gene is located at chromosome 2q22. Nonsense and frameshift mutations clustered in the C-terminus of the protein interfere with normal receptor internalization required to downregulate CXCR4-mediated signaling. As a result, there is an increase in the number of membranous CXCR4 receptors, leading to increased activation of the signaling pathway. CXCR4 mutations correlate with a subgroup of Waldenström macroglobulinemia patients with higher disease activity including higher disease burden, higher serum IgM levels, a greater extent of bone marrow infiltration, and a higher frequency of lymphadenopathy. ${ }^{87}$ CXCR4 mutations do not negatively impact overall survival, ${ }^{87}$ but are associated with resistance with BTK inhibitors ${ }^{88}$ (Figure 1 and Table 2). Strategies targeting both MYD88 signaling and CXCR4 may 
be needed in Waldenström macroglobulinemia patients with CXCR4 mutations. ${ }^{88,89}$

\section{Multiple Myeloma}

Multiple myeloma, also known as plasma cell myeloma, is a neoplasm of plasma cells that is driven by RAS pathway mutations and $M Y C$ translocations. ${ }^{90,91}$ Immunoglobulin genes are clonally rearranged and there is a high load of somatic hypermutation, suggesting that plasma cells are derived from a post-germinal center, antigen-driven B cell.

Cytogenetics subgroups and gene expression signature. The main clinically relevant molecular subgroups of multiple myeloma are defined by balanced translocations involving the IGH locus (Table 5). IGH translocations are present in $55-70 \%$ of multiple myeloma and there are five major recurrent oncogenes are involved in these translocations that account for about $75 \%$ of all translocations $(40 \%$ of multiple myeloma overall): CCND1/11q13), 15-25\%; MAF/16q23, 2-9\%; FGFR3/MMSET/ 4p16.3, 15\%; CCND3/6p21, 3\%; and MAFB/ 20q11, $2 \%$ (Table 5). Non-translocated cases of multiple myeloma are mostly hyperdiploid and usually show gains involving odd numbered chromosomes, 3, 5, 7, $9,11,15,19$, and $21 .^{3}$

Important independent negative prognostic indicators in patients with multiple myeloma include high risk $\mathrm{t}(4 ; 14)$ and the $M A F$ translocations $\mathrm{t}(14 ; 16)$ and $\mathrm{t}(14 ; 20)$, deletion of $17 \mathrm{p} / \mathrm{TP} 53$ sequences and increased serum levels of $\beta 2$-microglobulin. The $\mathrm{t}(4 ; 14)(\mathrm{p} 16.3 ; \mathrm{q} 32)$ juxtaposes IGH with FGFR3 and identifies a subgroup of high-risk multiple myeloma patients with shorter overall survival and progression-free survival. ${ }^{92}$ The NCCN guidelines recommend assessment for the following as a part of the initial work up: deletion of $17 \mathrm{p} 13$, deletion of chromosome 13, amplification of chromosome 1, $\mathrm{t}(11 ; 14)(\mathrm{q} 13 ; \mathrm{q} 32), \mathrm{t}(4 ; 14)(\mathrm{p} 16 ; \mathrm{q} 32)$, and $\mathrm{t}(14 ; 16)(\mathrm{q} 32$; q23). ${ }^{6}$ In addition to cytogenetic markers of prognosis, gene expression profiling studies allow identification of a high-risk molecular signature based on the expression of either 70 or 17 genes. The ratio of mean expression levels of upregulated genes mapped to chromosome 1q divided by mean expression levels of downregulated genes mapped to chromosome $1 \mathrm{p}$, define a high-risk score present in $13 \%$ of patients, with shorter durations of complete remission and shorter progression-free survival and overall survival. ${ }^{93}$ The NCCN guidelines state that gene expression profiling, although not used currently in the clinical practice, may be helpful in selected patients to estimate the aggressiveness of disease and individualize treatment. ${ }^{6}$

Specific mutations. Different genes have been found to be mutated in multiple myeloma cases with an appreciable frequency: KRAS, 21.2\%; NRAS, $19.4 \%$; DIS3, $10.36 \%$; TP53, 8\%; FAM $46 C, 5.4 \%$; BRAF, $6.7 \%$; TRAF3, 3.7\%); IRF4, $3.2 \%$; LTB, $3.0 \%$; CYLD, $2.4 \%$; and HIST1H1E, $2.6 \% .{ }^{94}$

The RAS/MAPK pathway is the most frequently mutated pathway, being altered in up to $43.2 \%$ of patients, with no correlation with overall survival. ${ }^{94}$ Activating mutations of KRAS and NRAS are thought to represent an early event in progression, mediating the transition from monoclonal gammopathy of undetermined significance to multiple myeloma. Other events involved in disease progression are secondary $I G H$ or $I G K / I G L$ translocations, deletion or mutation of TP53 (17p13), translocations involving $M Y C$, gains of chromosome 1q, loss of chromosome 1p, FGFR3 mutations in tumors with $\mathrm{t}(4 ; 14)$, and inactivation of $p 18 I N K 4 c$ or RB1. CXCR4 mutations are found in $20 \%$ of IgM monoclonal gammopathy of undetermined significance, but are absent in IgG or IgA monoclonal gammopathy of undetermined significance cases, identifying IgM monoclonal gammopathy of undetermined significance as being more closely related to lymphoplasmacytic lymphoma/ Waldenström macroglobulinemia or other B-cell lymphomas and segregated from the uniformly wild-type MYD88 IgG and IgA monoclonal gammopathy of undetermined significance cases that are more closely related to multiple myeloma. ${ }^{3}$ Mutated genes correlate with cytogenetic subgroups. Activating mutations of FGFR3 occur in $17 \%$ of the $t(4 ; 14)$ group. The $t(4 ; 14)$ translocation results in the ectopic expression of the receptor tyrosine kinase (RTK), fibroblast growth factor receptor 3 (FGFR3). Activated FGFR3 can be inhibited by tyrosine kinase inhibitors such as CHIR-258, representing a therapeutic target, as demonstrated by Trudel et al. ${ }^{95}$

CCND1, TP53, ATM, and ATR mutations have been associated with an adverse outcome. CCND1 mutations, present in $12 \%$ of the $\mathrm{t}(11 ; 14)$ subgroup, predict shorter overall survival (2-year overall survival $38.1 \%$ vs $80 \%))^{94} \operatorname{Del}(17 p)$ and $T P 53$ mutations also have a significant negative impact on outcome, showing an increased frequency at disease progression (26\%), as well as treatment refractoriness and other high-risk phenotypes (eg plasma cell leukemia). ATM mutations have been associated with an impaired progression-free survival (median, 15.4 vs 26.6 months) and shorter OS (2-year OS, $50 \%$ vs $80.3 \%$ ). Similarly, ATR mutations predict poorer prognosis $(1.5 \%$ of cases; median progression-free survival 23.9 vs 26.6 months; 2 -year OS, $67 \%$ vs $80 \%$ ). ${ }^{94}$

IRF4 and EGR1 mutations appear to have a positive impact on survival. IRF4 K123R mutations correlate with improved progression-free survival (2year progression-free survival, $71 \%$ vs $54 \%$; 2-year overall survival, $100 \%$ vs $79 \%$ ), as well as mutations in EGR1 (median progression-free survival $35.1 \mathrm{vs}$ 26.2 months; 2-year overall survival, $100 \%$ vs $78 \%$ ); EGR1 mutations have been described in hyperdiploid cases. ${ }^{94}$ Different treatments with small 
Table 5 Main translocations present in mature B-cell neoplasms

\begin{tabular}{|c|c|c|c|}
\hline Chromosomal translocations & Fusion genes & Entity (frequency) & Clinical utility \\
\hline \multicolumn{4}{|l|}{ IRF4 rearrangement } \\
\hline $\mathrm{t}(6 ; 7)(\mathrm{p} 25.3 ; \mathrm{q} 32.3)$ & DUSP22-FRA7H & ALK-ALCL (30\%) & Prognosis \\
\hline $\mathrm{t}(6 ; 14)(\mathrm{p} 25 ; \mathrm{q} 32)$ & IG-IRF4 & LBL with $I R F 4$ rearrangement & Diagnosis \\
\hline \multicolumn{4}{|l|}{ TP63 rearrangement } \\
\hline $\operatorname{inv}(3)(q 26 q 28)$ & TP63-TBL1XR1 & ALK-ALCL (8\%) & Prognosis \\
\hline \multicolumn{4}{|l|}{ MYC rearrangement } \\
\hline \multirow[t]{6}{*}{$\mathrm{t}(8 ; 14)(\mathrm{q} 24 ; \mathrm{q} 32)$} & $M Y C-I G H$ & BL $(90 \%)$ & Diagnosis \\
\hline & & DLBCL (5-15\%) & Prognosis \\
\hline & & HGBL, with $M Y C$ and $B C L 2$ and/or BCL6 & Diagnosis \\
\hline & & rearrangements $(100 \%)$ & \\
\hline & & FL (rare) & \\
\hline & & MCL (rare) & \\
\hline \multirow[t]{2}{*}{$\mathrm{t}(2 ; 8)(\mathrm{q} 12 ; \mathrm{q} 24)$} & $M Y C$-no partner & $\begin{array}{l}\text { MALT (rare) } \\
\text { BL (rare) }\end{array}$ & \\
\hline & identified & HGBL, with $M Y C$ and $B C L 2$ and/or BCL 6 rearrangements & Diagnosis \\
\hline \multirow[t]{2}{*}{$\mathrm{t}(8 ; 22)(\mathrm{q} 24 ; \mathrm{q} 11)$} & $M Y C$-no partner & BL (rare) & Diagnosis \\
\hline & identified & HGBL, with $M Y C$ and $B C L 2$ and/or BCL6 rearrangements & \\
\hline \multirow{2}{*}{\multicolumn{4}{|c|}{ BCL2 rearrangement }} \\
\hline & BCL2-IGH & DLBCL (20-30\%) & Diagnosis \\
\hline & & $\begin{array}{l}\text { HGBL with } M Y C \text { and } B C L 2 \text { and/or BCL6 rearrangements } \\
\text { FL }(90 \%)\end{array}$ & \\
\hline \multicolumn{4}{|l|}{ BCL6 rearrangements } \\
\hline \multirow[t]{3}{*}{ BCL6/3q27 } & No partner identified & DLBCL $(2 \%)$ & Diagnosis \\
\hline & & $\begin{array}{l}\text { HGBL, with } M Y C \text { and } B C L 2 \text { and/or BCL6 } \\
\text { rearrangements }(30 \%)\end{array}$ & \\
\hline & & MCL (rare) & \\
\hline $\mathrm{t}(3 ; 8)(\mathrm{q} 27 ; \mathrm{q} 32)$ & BCL6-IGH & DLBCL $(5-10 \%)$ & Prognosis \\
\hline \multicolumn{4}{|l|}{ CCND1 rearrangement } \\
\hline \multirow[t]{2}{*}{$\mathrm{t}(11 ; 14)(\mathrm{q} 13 ; \mathrm{q} 32)$} & CCND1-IGH & MCL > 90\% & Diagnosis \\
\hline & & MM (15-25\%) & Diagnosis \\
\hline \multicolumn{4}{|l|}{ CCND2 rearrangement } \\
\hline $\mathrm{t}(2 ; 12)(\mathrm{p} 12 ; \mathrm{p} 13)$ & $I G K-C C N D 2$ & MCL (rare, CCND1- cases) & Diagnosis \\
\hline $\mathrm{t}(12 ; 22)(\mathrm{p} 13 ; \mathrm{q} 22)$ & IGL-CCND2 & MCL (rare, CCND1 cases) & Diagnosis \\
\hline $\mathrm{t}(12 ; 14)(\mathrm{p} 13 ; \mathrm{q} 32)$ & IGH-CCND2 & MCL (rare, CCND1 cases) & Diagnosis \\
\hline \multicolumn{4}{|l|}{ CCND3 rearrangement } \\
\hline $\mathrm{t}(6 ; 14)(\mathrm{p} 21 ; \mathrm{q} 32)$ & IGH-CCND3 & MM (3\%) & Diagnosis \\
\hline \multicolumn{4}{|l|}{ Other tanslocations } \\
\hline $\mathrm{t}(11 ; 18)(\mathrm{q} 21 ; \mathrm{q} 21)$ & API2-MALT1 & MALT (0-52\%) & Diagnosis \\
\hline $\mathrm{t}(1 ; 14)(\mathrm{p} 22 ; \mathrm{q} 32)$ & & MALT $(5 \%)$ & Diagnosis \\
\hline \multicolumn{4}{|l|}{ Other IgH rearrangements } \\
\hline $\mathrm{t}(4 ; 14)(\mathrm{p} 16.3 ; \mathrm{q} 32)$ & FGFR3-IGH & MM (15\%) & Prognosis \\
\hline$t(14 ; 16)(q 32 q 23)$ & $I G H-C-M A F$ & MM (2-9\%) & Prognosis \\
\hline $\mathrm{t}(14 ; 20)(\mathrm{q} 32 ; \mathrm{q} 20)$ & $I G H-M A F B$ & MM $(2 \%)$ & Prognosis \\
\hline
\end{tabular}

Abbreviations: ALK+ ALCL: ALK-positive anaplastic large cell lymphoma; ALK - ALCL: ALK-negative anaplastic large cell lymphoma; BL: Burkitt lymphoma; DLBCL: diffuse large B-cell lymphoma; FL: follicular lymphoma; HGBL: high-grade B-cell lymphoma; LBL: large B-cell lymphoma; MALT: extranodal marginal zone lymphoma of mucosa-associated lymphoid tissues; MCL: mantle cell lymphoma; MM: multiple myeloma.

molecules targeting these mutations are a potential therapeutic option, and are being tested in different clinical trials. Small-molecule multi-targeted cyclindependent kinase (CDK) inhibitors trigger p53dependent and -independent anti-multiple myeloma activity. ${ }^{96}$ Deregulated RAS/MAPK and NF- $\kappa$ B pathways in multiple myeloma represent major potential therapeutic targets.
TP53 mutation status also might drive therapeutic decisions regarding consolidation and maintenance strategies in multiple myeloma patients. ${ }^{97}$ Nooka et $a^{97}$ suggested improvement in progression-free survival and overall survival among $17 \mathrm{p}$ deleted patients by using consolidation and maintenance therapy with lenalidomide, bortezomib, and dexamethasone, after high-dose chemotherapy and autologous stem cell 
transplantation in high-risk multiple myeloma patients compared with other strategies.

\section{Extranodal Marginal Zone Lymphoma of Mucosa-Associated Lymphoid Tissue}

Extranodal marginal zone lymphoma of mucosaassociated lymphoid tissue (MALT lymphoma) is a low-grade B-cell lymphoma arising in various extranodal organs, such as the stomach, lungs, salivary glands, ocular adnexae, and skin. MALT lymphoma is often associated with chronic inflammation or autoimmune diseases and accounts for about $8 \%$ of all cases of NHL. ${ }^{3}$ Immunoglobulin heavy- and light-chain genes are rearranged and show somatic hypermutation of the immunoglobulin gene variable regions, consistent with derivation from a post-germinal center memory B-cell.

Specific translocations. The $\mathrm{t}(11 ; 18)(\mathrm{q} 21 ; \mathrm{q} 21)$ occurs at different frequencies in MALT lymphoma arising at different sites, and leads to the generation of the BIRC3 (API2)-MALT1 (mucosa-associated lymphoid tissue lymphoma translocation) fusion gene $^{98}$ (Table 5). BIRC3 contains three aminoterminal baculovirus IAP repeats (BIRs), a central caspase recruitment domain (CARD), and a carboxyterminal zinc-binding RING finger domain. Breakpoints in BIRC3 occur downstream of the third BIR domain, upstream of the C-terminal RING domain, with $91 \%$ occurring just before the CARD domain. MALT1 is composed of an N-terminal death domain, followed by two Ig-like domains and a caspase-like domain. Four breakpoints have been identified in the introns upstream of the caspase-like domain. The translocation leads to the generation of a BIRC3MALT fusion transcript comprising the $\mathrm{N}$-terminal region of BIRC3 with three intact BIR domains and the C-terminal MALT1 region containing an intact caspase-like domain, which activates nuclear factor$\mathrm{kB}(\mathrm{NF}-\kappa \mathrm{B}){ }^{99}$ This translocation is most common in lung and stomach MALT lymphomas. In the stomach, translocations correlate with advanced stage disease and are less likely to respond to Helicobacter pylori eradication. The $\mathrm{t}(14 ; 18)(\mathrm{q} 32$; q21) translocation brings the MALT1 gene under the control of the enhancer region of $I G H$, causing its overexpression. ${ }^{99,100}$ This translocation seems to occur more frequently in non-gastrointestinal MALT lymphomas, such as the lungs and ocular adnexae. The $\mathrm{t}(3 ; 14)(\mathrm{p} 14.1 ; \mathrm{q} 32)$ occurs in MALT lymphomas of the thyroid gland, ocular adnexae, and skin. The $\mathrm{t}(1 ; 14)(\mathrm{p} 22 ; \mathrm{q} 32)$ translocation occurs in approximately $5 \%$ of intestinal MALT lymphomas, The translocation juxtaposes BCL1O with the IGH locus and deregulates BCL10 expression. ${ }^{99}$

$N F-\kappa B$ activation. MALT lymphoma is characterized constitutive activation of the NF- $\kappa \mathrm{B}$ pathway ${ }^{29,34,41}$ resulting from translocations or specific mutations.
As previously mentioned, BIRC3 and TRAF3 mutations in about $5 \%$ of cases are responsible for noncanonical NF- $\kappa \mathrm{B}$ pathway activation. Similarly, MALT lymphoma-associated chromosome translocations are capable of activating both canonical and non-canonical NF- $\kappa$ B pathways. ${ }^{101}$ Furthermore, TNFAIP3 (A20) inactivation by deletion and/or mutation abolishes the auto-negative feedback fostering $\mathrm{NF}-\kappa \mathrm{B}$ activation. Recurrent mutations in other NF- $\kappa \mathrm{B}$ regulators such as KMT2D/MLL2 (22\%), NFKBIE $(17 \%)$, BCL10 (14\%), MYD88 (7-9\%), NOTCH1 $(8 \%)$, and NOTCH2 (8\%) have been recently identified in MALT lymphomas. ${ }^{102,103}$

\section{Nodal Marginal Zone Lymphoma}

Specific gene mutations have been identified in nodal marginal zone lymphoma, an uncommon B-cell lymphoma that accounts for about $2 \%$ of all cases of NHL. The diagnosis of nodal marginal zone lymphoma relies mainly on morphological demonstration of marginal zone differentiation in the absence of extranodal or splenic disease. The immunophenotype of nodal marginal zone lymphoma is generally not specific; only a couple of molecules (MNDA and IRTA1) have been proposed as diagnostic markers, whereas B-cell receptor, JAK/ STAT, NF- $\kappa \mathrm{B}, \mathrm{NOTCH}$, and Toll-like receptor signaling pathways have been proposed to be the main deregulated pathways and potential targets for therapy. Given the significant overlap with other CD5-, CD10- low-grade B-cell lymphomas, the NCCN guidelines underline the potential utility of MYD88 and BRAF mutations status assessment in the differential diagnosis of nodal marginal zone lymphoma with Waldenström macroglobulinemia and hairy cell leukemia, respectively. ${ }^{4}$

The immunoglobulin genes are clonally rearranged with a predominance of mutated $\mathrm{VH} 3$ and VH4 families. ${ }^{104}$ A nodal marginal zone lymphoma molecular signature was described recently ${ }^{105}$ identifying features in common with other types of MZL (NOTCH2 and KLF2 mutations in 20 and $17 \%$ of nodal marginal zone lymphoma cases, respectively) and specific mutated genes such as PTPRD. $P T P R D$ encodes the receptor-type-protein-tyrosinephosphatase-d, a tumor-suppressor gene involved in cell growth regulation. PTPRD is somatically mutated in solid tumors, promoting tumorigenesis through Y705-phospho STAT3 activation. ${ }^{106}$ Truncating mutations (splice-site variant, missense substitutions) affecting the tyrosine phosphatase domain of the protein have been reported in $14.3 \%$ of nodal marginal zone lymphoma cases and appear to be specific for this entity. ${ }^{105}$

Inactivating mutations of KMT2D/MLL2, a tumorsuppressor histone-modifier gene located on chromosome 12q13, have emerged as the most frequent mutations in nodal marginal zone lymphoma, in $34 \%$ of cases in one study. ${ }^{107}$ Nonsense and 
frameshift- mutations affecting a residue within either the catalytic SET domain, the FYRC domain (FY-rich carboxy-terminal domain) or PHD zincfinger domains have been described ${ }^{107}$ (Figure 1 and Tables 3 and 4).

\section{Follicular Lymphoma}

Follicular lymphoma is a neoplasm composed of follicle center B-cells (centrocytes and centroblasts), usually with at least a partial follicular pattern, and accounts for $20 \%$ of all lymphomas worldwide. ${ }^{3,4}$ Follicular lymphoma is highly associated with the $\mathrm{t}(14 ; 18)(\mathrm{q} 32 ; \mathrm{q} 21)$ present in about $90 \%$ of all cases (Table 5). TNFRSF14 mutations have been described in $46 \%$ of the cases, and recurrent mutations of histone modifiers such as KMT2D (63\%), CREBBP (55\%), EP300 (14\%), EZH2 (89\%), ARIDIA (9\%), have been identified as early events in pathogenesis. ${ }^{108}$

Alterations deregulating cell-cycle progression and DNA-damage responses $(C D K N 2 A / B, M Y C$, TP53), as well as aberrant somatic hypermutation, are the most frequent genetics events found in transformed follicular lymphoma (tFL). ${ }^{109,110}$ Biallelic loss of $C K N 2 A / B$ is the most frequent finding (46\%), followed by $M Y C$ genetic deregulation (25-33\% of tFL) and TP53 mutations (17.9\%). ${ }^{109}$ Mutations in other genes such as B2M (13\%), CD58 (5.1\%), CCND3 (1\%), GNA13, S1PR2, and P2RY8 have also been reported at lower frequencies. ${ }^{109,111}$

Specific translocations. Most cases of follicular lymphoma carry the $t(14 ; 18)(q 32 ; q 21)$, which places the BCL2 gene at $18 \mathrm{q} 21$ adjacent to enhancer sequences of the $I G H$ at $14 q 32$, resulting in overexpression of bcl-2. ${ }^{112,113}$ FISH techniques can detect BCL2 translocations in up to $90 \%$ of follicular lymphoma, but more sensitive techniques, such as PCR can also be used to assess minimal residual disease (MRD). Breaks in chromosome 18 are localized at the 3'-UTR of BCL2 or downstream and are mainly clustered in either the major breakpoint region (mbr). There are also smaller clusters of breakpoints in the intermediate breakpoint cluster region (icr) and the minor breakpoint cluster region (mcr). Using polymerase chain reaction (PCR) analysis, $B C L 2 / J H$ involving the mbr can be detected in 60 to $70 \%$ of follicular lymphoma cases, respectively. ${ }^{114,115}$ BCL6 gene rearrangements also occur in $15-20 \%$ of cases of follicular lymphoma.

Chromatin modifier genes are the hallmark of germinal center-derived tumors. Results from NGS studies have shown that genes encoding chromatin modifiers such as histone acetyltransferases (CREBBP, EP300), and histone methyltransferases $(K D M 2 C / D, E Z H 2)$ are mutated at a high frequency in germinal-center-derived tumors, as has been reviewed by Lunning et al. ${ }^{108}$ Gain-of function mutations in EZH2, a H3K27 methyltansferase, lead to accumulation of the trimethylated form of the protein and repression of cell-cycle inhibitors (CDKN1A and CDKN2A/B genes). ${ }^{116,117}$ EZH2 mutations have been identified in $89 \%$ of follicular lymphoma cases and are thought to be a common early event in pathogenesis. ${ }^{77,118}$ EZH2 mutations are potentially targetable with selective EZH2 inhibitors. ${ }^{75,76}$ These data suggest that chromatin modifier mutations could be the hallmark of germinal center-derived tumors (Table 3).

$C D K N 2 A / B$. The tumor-suppressor genes $C D K N 2 A$ and $C D K N 2 B$ encode proteins that participate in DNA damage responses (via the p14-ARF/p53 pathway) as stabilizers of the tumor-suppressor p53, and cell-cycle regulation as negative regulators of cell-cycle G1 progression (via the RB/p16 tumor suppressive pathway). Biallelic loss of $C D K N 2 A / B$ has been demonstrated to be specifically acquired during follicular lymphoma transformation. Genomic alterations affecting these loci (copy number losses, nonsense mutations and copy number loss of heterozygosity have been reported in up to $46 \%$ of tFL. ${ }^{109}$

MYC and TP53. Genetic lesions deregulating MYC are important in disease progression. Chromosomal translocations and copy number gains/amplifications have been reported in $25 \%$ and $33 \%$ of tFL cases. ${ }^{109}$ TP53 mutations also identify a subgroup of patients with high-risk follicular lymphoma. About $6 \%$ of follicular lymphoma cases carry TP53 mutations which are associated with older age at diagnosis, higher International Prognostic Index score, and shorter overall survival and progressionfree survival (Figure 1 and Table 2). ${ }^{119}$ Transformed follicular lymphoma cases are enriched for TP53 mutations $(17.9 \%)^{109}$ and therefore TP53 mutation analysis is useful for prognostication and therapeutic decision making.

\section{Large B-Cell Lymphoma with Irf4 Rearrangement}

Chromosomal translocations juxtaposing the IRF4 oncogene next to one of the immunoglobulin loci were recently described as a novel recurrent aberration in mature B-cell lymphoma. The $\mathrm{t}(6 ; 14)$ (p25;q32)/IRF4-IGH has been identified in $8 \%$ of germinal-center lymphomas and is associated with a young age at presentation and a favorable outcome. These cases were predominantly germinal center B-cell-like DLBCL or follicular lymphoma grade 3, with strong expression of IRF4/MUM1 and BCL6, and lack of PRDM1/BLIMP1 expression and $t(14 ; 18) /$ BCL2 breaks. ${ }^{120}$ Thus, the $\mathrm{t}(6 ; 14)(\mathrm{p} 25 ; \mathrm{q} 32)$ identifies a new provisional entity in the 2016 update of the WHO classification under the name 'large B-cell lymphoma with IRF4 rearrangement' (Table 5). 


\section{Pediatric-Type Follicular Lymphoma}

Pediatric-type follicular lymphoma has been included as an entity in the 2016 WHO update. These tumors usually occur in children, but rarely adults are affected. Patients with pediatric-type follicular lymphoma usually present with localized disease and have an indolent clinical course. Therefore, surgical excision alone, without chemotherapy, is often adequate for patient management.

Pediatric-type follicular lymphoma is characterized by large, expansile, highly proliferative follicles composed of large or blastoid follicular center cells. The proliferation rate as shown by Ki-67 is often high and these tumors often do not express BCL2 protein and do not carry BCL2, BCL6 or $M Y C$ rearrangements. ${ }^{121-123}$

The gene mutation findings in pediatric-type follicular lymphoma are distinctive. This entity is characterized by frequent mutations in the MAPK pathway, and absence of mutations that are common in the usual type of follicular lymphoma, such as mutations in epigenetic modifiers like CREBBP and KMT2D. ${ }^{124}$ Activating mutations in MAP2K1 are most common, in $43 \%$ of cases in one study. These mutations occur in exons 2 and 3 of $M A P 2 K 1$, which encodes MEK1 protein, affecting the negative regulatory region and catalytic domain of the protein, respectively. Other mutations in this pathway also occur uncommonly, including MAPK1 or RRAS. ${ }^{125}$ TNFRSF14 is the second gene most frequently mutated in pediatric-type- follicular lymphoma, being found in $29 \%$ of the cases. ${ }^{124,125}$

\section{Predominantly Diffuse Follicular Lymphoma with 1 p36 Deletion}

Another distinctive group of follicular lymphoma is also recognized in the 2016 WHO update, designated as 'predominantly diffuse follicular lymphoma with 1 p36 deletion'.3 These tumors usually present as large inguinal masses. Histologically, these tumors have a diffuse pattern, are often low grade, usually express CD23 in addition to germinal center B-cell antigens, usually lack BCL2 rearrangements, and commonly exhibit 1 p36 deletions. ${ }^{126}$ At the genetic level, these tumors carry STAT6 mutations at a high frequency, over $82 \%$ in one study, a substantially higher frequency than observed in usual cases of follicular lymphoma. ${ }^{127}$

\section{Mantle Cell Lymphoma}

Mantle cell lymphoma is an aggressive small B-cell neoplasm that accounts for approximately $4 \%$ of NHL cases. ${ }^{3}$ The $\mathrm{t}(11 ; 14)(\mathrm{q} 13 ; \mathrm{q} 32)$ juxtaposes CCND1 at $11 \mathrm{q} 13$ with $I G H$ on the derivative chromosome 14 and plays a key role in mantle cell lymphoma pathogenesis. Mantle cell lymphoma shows a poor prognosis with a median overall survival of about 3 years, and is characterized by continuous relapses and increasing resistance to chemotherapy. ${ }^{128}$ Nevertheless, a subset of mantle cell lymphoma cases carry mutated $I G H V^{129,130}$ and do not express SOX11.131,132 Patients with these tumors follow a more clinically indolent course with stable disease, even in the absence of chemotherapy. ${ }^{133,134}$

A number of recurrently mutated genes have been described in mantle cell lymphoma, including $A T M$ (45\%), MEF2B (37\%), CCND1 (18-35\%), CDKN2A/ $B / C$ (25\%), WHSC1 (25\%), MAP3K14 (24\%), RB1 (26\%), TP53 (7-20\%), CDK4 (20\%), and PLCG (20\%), POT1 (20\%), KNT2C/MLL3 (16\%), KMT2D/ MLL2 (14\%), BIRC3 (15\%), NOTCH1 (12\%), NOTCH2 (5.2\%), CARD11 (5.5\%), and RELA (2\%). Only, CCND1, NOTCH1, NOTCH2 and TP53 mutations have been shown to correlate with poorer overall survival in mantle cell lymphoma patients (Figure 1 and Table 2). ${ }^{39,133,135-139}$

CCND1 rearrangement. The specific chromosomal translocation $t(11 ; 14)(q 13 ; q 32)$, that leads to cyclin D1 overexpression in mantle cell lymphoma includes many different breakpoints. Approximately $30-50 \%$ of breakpoints are located in a 2-kilobase region referred to as the major translocation cluster (MTC). ${ }^{140-142}$ The translocation partner is $I G H$ at chromosome $14 q 32^{140}$ (Table 5). The breakpoints within IGH occur in a chromosomal region 5 ' of the joining genes $(\mathrm{JH})$, joining the CCND1 to the enhancer of $I G H$ complex at the 3' site of the $\mathrm{JH}$ region. More breakpoints also have been localized within the close vicinity of the 5'-end of the CCND1 gene. Thus, multiple breakpoints are present over a large region, and, therefore, many probes are necessary to cover all breakpoints in a PCR-based assay.

BIRC3. BIRC3 mutations were identified in approximately $15 \%$ of cases of mantle cell lymphoma, in association with MAP3K14-dependent NF- $\kappa$ B pathway activation and ibrutinib insensitivity. ${ }^{143}$ Transcriptome sequencing of wild-type BCR signaling inhibitor-sensitive mantle cell lymphoma cell lines revealed chronic activation of the BCR-driven classical nuclear factor $\kappa \mathrm{B}$ pathway, whereas insensitive cell lines carrying BIRC3 mutations displayed activation of the alternative $\mathrm{NF}-\kappa \mathrm{B}$ pathway. ${ }^{143}$ These results suggest that $B I R C 3$ aberrations in mantle cell lymphoma may result in decreased sensitivity to ibrutinib, and that protein kinase MAP3K14 could be a potential therapeutic target in BIRC3-mutated lymphomas $^{143}$ (Figure 1 and Tables 2 and 3).

CCND1. CCND1 mutations, resulting in cyclin D1 overexpression, are associated with a higher proliferation index, shorter overall survival, and ibrutinib resistance ${ }^{118,144}$ (Figure 1, Tables 2 and 3 ).

Two different genomic events can lead to an increased expression of cyclin D1. First, genomic deletions and point mutations of the $3^{\prime} \mathrm{UTR}$ region 
result in the generation of shorter and more stable mRNA transcripts lacking the destabilizing AU-rich elements. Second, deletions or point mutations in the translated exons of CCND1 can be seen in $22 \%$ of mantle cell lymphoma cases and are associated with an adverse prognosis ${ }^{118,145}$ (Figure 1 and Table 2). Recent large-scale genomic studies identified a hotspot for recurring somatic mutations in exon 1 of CCND1 in 18-35\% of cases ${ }^{136,138,139}$ (Table 2). The three most frequent CCND1 mutations (E36K, Y44D, and C47S) in mantle cell lymphoma cell lines induce a decrease in protein proteolysis through the ubiquitin-proteasome pathway, leading to the stabilization of CCND1 in the nucleus. These mutations are associated with increased resistance to ibrutinib $^{144}$ (Figure 1 and Tables 3 and 4).

TP53. TP53 mutations have been identified in $7-20 \%$ of mantle cell lymphoma cases, ${ }^{132,136,137}$ in the same hotspots described previously in the literature for chronic lymphocytic leukemia, and are associated with a poorer prognosis. ${ }^{146,147}$ Halldorsdottir et $a l^{137}$ reported the largest series of mantle cell lymphoma cases in which the frequency of TP53 mutation and the prognostic impact of TP53 and $17 p$ deletions were studied. Their series was composed of 119 cases of mantle cell lymphoma, including 84 classical and 34 blastoid variant, in which assessment of exons 4-8 showed non-silent TP53 mutations affecting the classical hotspots in $14 \%$ of cases. ${ }^{147,148}$ Missense mutations were most frequent followed by nonsense mutations; most mutations were transitions, predominantly GC $>$ AT transitions at $\mathrm{CpG}$ methylated sites, most commonly in exons 5 and 8 . The codons most commonly mutated were at positions 176,248 , and 273. The presence of TP53 mutations was associated with significantly decreased overall survival (13 vs 43 months) (Figure 1 and Table 2). The presence of $17 p$ deletions did not appear to have any prognostic impact on mantle cell lymphoma. Some groups had previously described the presence of TP53 mutations or 17p deletions in association with the clinically aggressive blastoid variant of mantle cell lymphoma, ${ }^{138,149}$ but this observation was not confirmed in the study performed by Halldorsdottir et $a{ }^{137}$ in which classic and blastoid mantle cell lymphoma cases had similar mutation frequencies (13\% vs 18\%). Targeted therapy directed at TP53 mutations could be an option in patients with aggressive clinical behavior and poorer outcome.

Somatic hypermutations and IGHV utilization. Most cases of mantle cell lymphoma carry unmutated IGHV genes, but up to $40 \%$ of cases show somatic hypermutation. Mutated IGHV genes correlate with a more indolent clinical course. Biased use of the $V H$ genes also has been reported in mantle cell lymphoma. Thorselius et $a 1^{150}$ described restricted usage of three individual VH genes: VH4-34 (22\%), VH3-21 (16\%), and VH5-51 (12\%). The finding of preferential VH gene usage supports the hypothesis that a subset of mantle cell lymphoma cases is an antigen-driven process occurring in B cells expressing specific VH genes, thus implicating Ig specificity in mantle cell lymphoma development. VH3-21 usage occurs in unmutated cases and correlates with a better prognosis and a reduced number of chromosomal imbalances, compared with mantle cell lymphoma utilizing other immunoglobulin $\mathrm{VH}$ genes. ${ }^{151}$

\section{Diffuse Large B-Cell Lymphoma}

DLBCL is the most common type of lymphoid malignancy worldwide, accounting for about onethird of all NHL cases. ${ }^{4}$ DLBCL is characterized by an aggressive clinical course, and exhibits marked heterogeneity in clinical, morphologic, and molecular findings.

Gene expression profiling studies identified three distinct molecular subgroups of DLBCL with different outcomes and pathogenic mechanisms: ${ }^{85,151-153}$ germinal center B-cell like (94\% 5-year overall survival), activated B-cell like (68\% 5-year overall survival), ${ }^{154,155}$ and an unclassifiable group. Subsequently, the latter group was shown to include cases of primary mediastinal large B-cell lymphoma (64\% 5-year overall survival). ${ }^{151-153}$ In activated B-cell-like DLBCL the $\mathrm{NF}-\kappa \mathrm{B}$ pathway is activated and NGS studies identified, non-synonymous missense substitutions affecting $C D 79 A / B \quad(20 \%)$, $C A R D 11(10 \%)$, and other pathway genes as the explanation $^{156-158}$ (Figure 2). Many other mutations have been described in DLBCL, with diverse clinical implications, and gene mutations correlate in part with cell-of-origin classification: STAT6 (36\%), TNFAIP3 (36\%), PIK3CA/D (40\%), PIM1 (25\%), KMT2C/MLL3 (23\%), SOCS1 (17\%), PRDM1 (12\%), KMT2D/MLL2 (24\%), PTEN (22\%), TNFRSF14 (22\%), CCND3 (18\%), and MEF2B (18\%). ${ }^{159}$ TP53 mutations identified in $20 \%$ of DLBCL cases of either germinal center B-cell like or activated B-cell like type are important because their presence is an independent predictor of worse outcome. ${ }^{160,161}$ MYD88 mutations (30-40\%) are increased in activated B-cell-like DLBCL in association with an adverse clinical presentation and poor outcome. ${ }^{78,162-164}$ In contrast, germinal center B-cell-like DLBCL is associated with mutations involving histone modification and acetylation (EZH2) and $M Y C$ translocations. Heterozygous somatic gain-of-function point mutations affecting the EZH2 Y641 residue are also specific for the germinal center B-cell-like DLBCL subtype, and are present in $30 \%$ of the cases ${ }^{77,165}$ (Table 3).

Specific translocations. In DLBCL, translocations involving $B C L 2$ or $M Y C$ are present in $20 \%$ and 5-10\% of cases, respectively, whereas BCL6 translocations involving many different partners are present in about $30 \%$ of cases. IG-associated BCL6 
translocations occur in $5-10 \%$ of DLBCL. ${ }^{166,167}$ A number of rare $I G$ locus-associated translocations involving other partner genes have been identified in DLBCL, including BCL3, BCL8, BCL11A, CCNE1, CCND3, EBF1, FOXP1, IRF8, NFKB2, RCK, SPIB, and TNFSF13. Most translocations that involve $M Y C$ in DLBCL involve one of the immunoglobulin loci, but other partner loci, in particular the BCL6 locus and a chromosomal region in 9p13 in the vicinity of the PAX5 gene ${ }^{168}$ (Table 5) can also be involved. Importantly, the co-occurrence of MYC translocation with translocations involving BCL2 or BCL6 or both, so-called double or triple hit lymphoma, identified a subset of highly aggressive B-cell lymphomas that can have DLBCL-like or Burkitt-like morphology. ${ }^{169}$ The 2016 update of the WHO includes a provisional new category designated as high-grade B-cell lymphoma with MYC and BCL2 and/or BCL6 rearrangements for these neoplasms. ${ }^{3}$

$C D 79 A / B$ and $C A R D 11 . \quad C D 79 A$ and $C D 79 B$ mutations are present in up to $20 \%$ of activated B-cell-like DLBCL cases. ${ }^{157}$ Non-synonymous missense substitutions affecting the CD79A and CD79B ITAM domains enhance BCR signaling, suppress the negative regulation of LYN kinase, and decrease BRC internalization after its ligand activation. ${ }^{157}$ CARD11 mutations also sustain NF- $\kappa \mathrm{B}$ activation in activated B-cell-like DLBCL in 10\% of the cases. ${ }^{156,158}$ CARD11 encodes a multi-domain protein that takes part in a signaling complex required for NF- $\mathrm{B}$ signaling downstream of the BCR receptors. CARD11 mutants promote spontaneous multimerization of the complex, association with BCL10 and IKKB activation, leading to NF- $\kappa \mathrm{B}$ signaling pathway activation in a BCR-independent manner. ${ }^{156}$

Thus, chronic active BCR signaling in activated B-cell-like DLBCL may be targeted by inhibitors of upstream components of the signaling pathway, such as BTK, SYK, SRC family kinases, $\operatorname{PKC} \beta$, and PI3KY. ${ }^{170}$ There are currently several ongoing clinical trials using kinase inhibitors that show promising results for DLBCL targeted therapy in relapsed or refractory cases. Ibrutinib, a selective BTK inhibitor, showed selective toxicity in activated B-cell-like DLBCL cells and good results in phase I/II trials. ${ }^{171}$ PI3K can also be targeted with a specific inhibitor, idelalisib (GS-1101), that showed AKT and NF- $\kappa$ B downstream signaling inhibition and activated B-cell-like DLBCL lymphoma cell death in preclinical experiments. ${ }^{171}$ Inhibition of IRAK4, downstream of MYD88, also has been shown to be effective in NF- $\kappa \mathrm{B}$ inactivation in DLBCL and Waldenström macroglobulinemia cells harboring MYD88 mutations (Table 3).

MYD88. Some studies have suggested that MYD88 L265P mutations identify a subgroup of patients with DLBCL, mainly of activated B-cell-like origin, with a poor outcome. In a study performed by Rovira et $a l^{162}$ MYD88 mutations were seen in $22 \%$ of the cases, most of which were activated B-cell-like type. Mutated tumors occur more often in older patients with more advanced stage disease, frequent extranodal involvement, and higher International Prognostic Index scores. MYD88 L265P mutations correlated with a worse clinical outcome and shorter OS (52\% 5-year OS vs 75\%) (162 $^{16}$ (Table 2 and Figure 1). Therefore, MYD88 mutational status represents a useful prognostic indicator in DLBCL patients, allowing the identification of a subgroup with extranodal involvement and poor outcome. Moreover, somatically acquired MYD88 mutations have been shown to promote NF- $\kappa$ B and JAK-STAT3 signaling in activated B-cell-like DLBCL. ${ }^{163,172}$ Therefore, patients with activated B-cell-like DLBCL with MYD88 L265P mutations may benefit from therapies targeting IRAK4 alone or in combination with agents targeting the B-cell receptor, ${ }^{157}$ NF- $\kappa \mathrm{B},{ }^{173,174}$ or JAK-STAT3 pathways. ${ }^{163}$

TP53. TP53 mutational status is an independent prognostic indicator of poor survival in patients with DLBCL. ${ }^{160,161,175-177}$ Clinically, TP53 mutations are associated with a younger age at diagnosis, high serum LDH level, bulky tumors, and high international prognostic index risk group ${ }^{161}$ (Figure 1 and Table 2). The domain location of TP53 mutations plays a critical role in determining clinical outcome. ${ }^{161}$ TP53 mutations occur in about $20 \%$ of DLBCL patients and mutations in exons 5-9 affecting the DNA-binding domain resulting in a loss of function have been associated with a significant worse overall survival in DLBCL patients. ${ }^{160,161,178}$ Mutations in loop 1, loop 3, and LSH (codons 272287), which are essential for DNA binding, ${ }^{179,180}$ correlate with a poorer median and 5-year OS. In contrast, TP53 mutations in loop 2 have minimal impact on overall survival ${ }^{161}$ (Figure 3). TP53 mutational status also allows stratification of patients with germinal center B-cell-like DLBCL into two different prognostic subgroups, predicting for poorer overall survival in the TP53 mutated subset.

Others have proposed that TP53 mutations may confer a selective survival advantage for lymphoma cells during chemotherapy, enhancing resistance to drug-induced apoptosis, ${ }^{181}$ and predict poorer overall survival and progression-free survival in DLBCL patients treated with R-CHOP. ${ }^{182}$ Thus, TP53 mutations contribute to the risk stratification of patients with DLBCL, representing a potential therapeutic target in patients with DLBCL. ${ }^{183,184}$

\section{Burkitt Lymphoma}

In Burkitt lymphoma, t(8;14)(q24;q32) involves $M Y C$ at chromosome $8 \mathrm{q} 24$ and the IGH locus at chromosome $14 \mathrm{q} 32$ and accounts for approximately $90 \%$ of all cases (Table 5). There are also two variant translocations, $\mathrm{t}(2 ; 8)(\mathrm{q} 12 ; \mathrm{q} 24)$ and $\mathrm{t}(8 ; 22)(\mathrm{q} 24 ; \mathrm{q} 11)$ in Burkitt lymphoma. In $\mathrm{t}(8 ; 14), M Y C$ resides on the 
derivative chromosome 14 but in the variant translocations $M Y C$ resides on the derivative chromosome 2 (IGK) or 22 (IGL), respectively. MYC consists of three exons, among which exons 2 and 3 include the coding sequence for the protein. The negative regulatory exon 1 and intron 1 sequences are removed in some lymphomas because the $\mathrm{t}(8: 14)$ breakpoints tend to be in the first intron. ${ }^{147}$ Translocations occur in a head to head $\left(5^{\prime}-5^{\prime}\right)$ fashion between the two loci of $M Y C$ and IGH. The IGH enhancer elements affect the transcription of $M Y C$ resulting in $M Y C$ overexpression. ${ }^{185}$ Primers flanking the breakpoints in exon 2 of $M Y C$ and for the joining and constant regions of IGH (CH1 exons of IGHG or in the sixth joining segment of IGHJ) can be used to detect the $\mathrm{t}(8: 14) .{ }^{186} \mathrm{MYC}$ translocations also can be found in $2-5 \%$ of DLBCL, a subset of cases of B prolymphocytic leukemia and chronic lymphocytic leukemia, and rare cases of follicular lymphoma and mantle cell lymphoma. ${ }^{187-190}$

EBV status likely impacts the occurrence of genetic alterations in Burkitt lymphoma. In the endemic cases, EBV-positive MYC/Ig breakpoints originate from aberrant somatic hypermutation, while in the EBV-negative sporadic cases, MYC translocations mostly involve the Ig switch regions of the IGH locus. ${ }^{191,192}$ In EBV-positive tumor cells, the growth-transforming program of viral gene expression (latency III) is extinguished, and only the EBV nuclear antigen (EBNA)1 is expressed via the alternative latency I program. Gene expression profiling studies in EBV-positive and -negative BL found significant differences in the expression of viral micro-RNAs and in selected target genes: LIN28B, CGNL1, GCET2, MRAS, PLCD4, SEL1L, SXX1, STK10/STK33L. These findings demonstrated significant differences in the transcriptional profiles of EBV-positive and EBV-negative Burkitt lymphoma cases, suggesting that EBV infection may play a critical role, by itself, in Burkitt lymphoma L pathogenesis, precluding the need for additional mutations. ${ }^{193}$

NGS studies have disclosed the importance of the BCR pathway in the pathogenesis of Burkitt lymphoma. ${ }^{194,195}$ Activation of the $M Y C$ protooncogene at $8 \mathrm{q} 24$ via chromosomal translocation with one immunoglobulin locus is almost universal, but recent studies have shown the existence of regulatory pathways cooperating with MYC in Burkitt lymphoma pathogenesis. ${ }^{196}$ The most frequently mutated genes in Burkitt lymphoma are TP53 (69\%), ID3 (58\%), MYC (40\%), CCND3 (38\%), CDK4 (17\%), GNA13 (10.5\%), CREBBP (6\%), PIK3R1 (2\%), and tumor-suppressor genes such as ARID1A $(7 \%)$, and SMARCA4 $(21 \%){ }^{194}$

Schmitz et al ${ }^{165}$ reported mutations affecting the TCF3 gene or disrupting its negative regulator, ID3, in $70 \%$ of Burkitt lymphoma cases. These alterations result in a constitutive BCR tonic activation, and thus provide a potential mechanism for PI3K activation in human Burkitt lymphoma. ${ }^{165,197}$ TCF3 is a member of the helix-loop-helix transcription factor family. TCF3 activates transcription by binding to regulatory E-box sequences on target genes, as heterodimers or homodimers, and is inhibited by heterodimerization with inhibitor of DNA-binding (class IV) helix-loop-helix proteins. Thus, inhibitor of DNA-binding (ID) proteins, such as ID3, can bind TCF3 via the helix-loop-helix motif common to both and inhibit TCF3 function. ID3 mutations affecting the helix-loop-helix domain are mainly represented by nonsense and frameshift mutations, as well as somatic missense mutations (encoding a R606Q change), ${ }^{189}$ with a silencing effect on the gene. ${ }^{198}$ The overall consequence of ID 3 and TCF3 mutants in Burkitt lymphoma is an impairment of TCF3/ID3 inhibitory heterodimerization, leading to a tonic BCR signaling in an antigen-independent manner upon release from the ID3-TCF3 heterodimer (Figure 2 and Table 3).

\section{Burkitt-Like Lymphoma with 11q Aberration}

Burkitt-like lymphoma with $11 \mathrm{q}$ aberration was introduced in the 2016 update of the WHO classification of lymphoid neoplasms ${ }^{3}$ as a provisional entity, identifying a subgroup of lymphomas with morphologic and clinical features of Burkitt lymphoma, lacking $M Y C$ translocations. Burkitt-like lymphoma cases are frequently found in immunodeficient hosts, in association with a specific pattern of aberrations in chromosome 11 (interstitial gains including 11q23.2-q23.3 and telomeric losses of 11q24.1-qter). ${ }^{116,117}$

\section{Genomic Features of Hodgkin Lymphoma}

The paucity of Hodgkin and Reed-Sternberg (HRS) cells in classical Hodgkin lymphoma (HL) and lymphocyte predominant cells in nodular lymphocyte predominant HL cells has made the study of recurrent genetic alterations involved in pathogenesis highly challenging. Mutations in activators or inhibitors of apoptosis such as TP53, FAS, caspase 8 , caspase 10, FAS-associated via death domain $(F A D D)$, BCL-2 agonist of cell death $(B A D)$ or ataxia-telangiectasia mutated $(A T M)$ as well as translocations involving $B C L 2$, have been found in HRS cells and HL cell lines supporting the hypothesis that rescue of HRS cells from apoptosis is probably a key event in HL pathogenesis. ${ }^{199}$

A consistent feature of HRS cells in classical HL is constitutive activation of the NF- $\kappa$ B pathway, which can be the result of different types of genetic alterations. Genomic gains and amplifications of $R E L$ and translocation involving $B C L 3$ are observed in $50 \%$ and $10 \%$ of HL cases, respectively, leading to upregulation of the pathway. Mutations in the negative regulators NFKBIA, NFKBIE, and TNFAIP3 (A20) have been described in $20-60 \%$ of HL cases, also contributing to NF- $\kappa \mathrm{B}$ pathway upregulation. ${ }^{199}$ 
Both the canonical and non-canonical pathways of $\mathrm{NF}-\kappa \mathrm{B}$ are also activated by members of the TNFR family, such as CD30, CD40, TNFRSF13B or TACI, BCMA or TNFRSF17 and RANK (TNFRSF11A).

The JAK-STAT pathway is frequently activated by both genetic lesions and by autocrine and/or paracrine signaling. Many cytokines activate members of the JAK family, inducing the phosphorylation of STAT factors that dimerize and translocate to the nucleus, acting as transcription factors. Furthermore, genomic gains of JAK2 are frequently seen in HRS cells, as well as mutations in the negative regulator suppressor of cytokine signaling 1 (SOCS1). ${ }^{199}$ Mutations of protein tyrosine phosphatase nonreceptor 1 (PTPN1), an inhibitor of the JAK-STAT pathway, occur in about $20 \%$ of cases. ${ }^{200}$ The PI3KAkt pathway, and the erk pathway, as well as AP1 and multiple receptor tyrosine kinases have also been shown to be deregulated in HRS cells. ${ }^{199}$

The tumor microenvironment and interaction with HRS cells is also important in pathogenesis. HRS cells overexpress PD-L1 and PD-L2, usually as a result of amplification or translocation involving chromosome $9 \mathrm{p} 24 .^{201}$ Translocations involving CIITA, a coactivator of the promoter of MHC class II at chromosome 16p13.13, also occur in about $20 \%$ of cases of classical HL. ${ }^{202}$

\section{Emerging Applications of Molecular Testing in Lymphoma}

MRD monitoring. The assessment of MRD by realtime quantitative polymerase chain reaction-based techniques has emerged as a widely feasible and standardized tool for direct assessment of therapyinduced reduction of tumor burden and regrowth after treatment in lymphoma, with much improved sensitivity compared with conventional staging procedures. With the exception of follicular lymphoma, where MRD is typically assessed by amplifying the $\mathrm{t}(14 ; 18)$ translocation, IGH-based MRD is the most established and widely employed method for MRD detection and monitoring in lymphoid neoplasms

During early B- and T-cell differentiation, the germline variable (V), diversity (D), and joining (J) gene segments of the immunoglobulin and T-cell receptor genes rearrange and each lymphocyte thereby obtains a particular combination of $\mathrm{V}-(\mathrm{D}-)$ J segments. Clonal antigen receptor gene rearrangements can be amplified by PCR: IGH, IGK, IGL, TRG, TR delta, and TRB gene rearrangements can be analyzed in a multiplex approach as stated in the BIOMED-2 consensus. ${ }^{203}$ Discrimination between monoclonal and polyclonal PCR products is required and can be achieved by heteroduplex analysis or fluorescent gene scanning. ${ }^{204}$ However, PCR amplification of IGH or T-cell receptor gene rearrangements does not allow sequencing of the tumor clonotype, which is sometimes necessary for MRD determination. ${ }^{205,206}$ Patient-specific clonal rearrangements of the $I G H$ or T-cell receptor genes can be tracked by sequencing the specific PCR products and designing clone-specific primers, which represents a laborious and time-consuming practice.

Conventional PCR-based MRD detection has a number of limitations, including failure of marker identification in somatically hypermutated tumors and cases with low tumor percentage. Recently, NGS-based methods have been developed to overcome these limitations and are emerging as a reliable tool to quantify the T-cell receptor and IGH repertoires. ${ }^{207-209}$ Different studies comparing NGSbased methods and allele-specific oligonucleotides PCR for MRD assessment have shown excellent concordance between the results obtained using both methods. ${ }^{209-211}$ Thus, NGS approaches may have some advantages in terms of achieving a higher level of sensitivity (up to $1 \times E-06$ ), avoiding the use of patient-specific reagents. ${ }^{209,210}$ NGS techniques for MRD assessment have also extended our current understanding of genetic diversity and disease biology. With increasing adoption of NGS-based methodologies in routine clinical testing, NGSbased MRD monitoring of lymphoma is likely to increase.

Liquid biopsy. With the emergence of targeted therapy, genotyping tumor tissue in search of somatic genetic alterations for actionable information is currently routine practice in clinical oncology. Although this information has been obtained traditionally by assessment of a tissue biopsy specimen, biopsy specimens are difficult to obtain serially, and are prone to sampling bias. Cells undergoing apoptosis or necrosis are shed into the bloodstream, and the load of circulating cell-free DNA correlates with tumor staging and prognosis. ${ }^{212}$ Nowadays, genotyping circulating cell-free DNA for somatic genomic alterations found in tumors is possible, as well as detection and quantification of somatic mutations that can be tracked in liquid biopsies in solid tumors. Therefore, circulating tumor DNA or circulating cell-free DNA can provide information about the tumor clonal heterogeneity in a non-invasive way, also allowing the study of changes over time.

Regarding lymphomas, plasma circulating cell-free DNA genotyping has been shown to be a useful tool for detecting clonal somatic mutations in DLBCL, and for tracking clonal evolution and emergence of treatment-resistant clones in DLBCL. Rossi et al $2^{213}$ performed a longitudinal analysis to identifying DLBCL-associated mutations in pre-treatment circulating cell-free DNA from DLBCL patients using ultra-deep targeted next-generation sequencing. These mutations were cleared in subsequent plasma samples from R-CHOP responding patients, and persisted among patients with resistant disease. Furthermore, new mutations among resistant clones were identified. Circulating cell-free DNA 
genotyping is rapidly emerging as a minimally invasive diagnostic tool to detect and track somatic mutations and emergence of treatment-resistant clones.

\section{Conclusion}

An unprecedented number of novel diagnostic, prognostic and predictive molecular biomarkers have recently been identified in B-cell lymphomas, several of which have already been included in the last update of the NCCN guidelines and 2016 WHO classification of lymphoid neoplasms ${ }^{4}$ (Table 2). Novel targeted therapies based on the new molecular alterations are promising to change the therapeutic landscape for patients with B-cell mature neoplasms. ${ }^{2}$ At the same time, advances in clinical laboratory technologies are enabling ultrasensitive screening of multiple biomarkers in a variety of sample types in routine clinical care of a broad spectrum of mature B-cell neoplasms. In conclusion, accelerated biomarker discovery, prompt integration in consensus evidence-based clinical practice guidelines, and development of clinical laboratory tools continue to drive the integration of molecular biomarkers in modern lymphoma care.

\section{Acknowledgments}

AO is funded by a post-residency contract 'Wenceslao lopez-Albo' provided by Instituto de Investigacion Marques de Valdecilla (Santander, Spain).

\section{Disclosure/conflict of interest}

The authors declare no conflict of interest.

\section{References}

1 Gruber M, Wu CJ. Evolving understanding of the CLL genome. Semin Hematol 2014;51:177-187.

2 Kraan W, Horlings HM, van Keimpema M, et al. High prevalence of oncogenic MYD88 and CD79B mutations in diffuse large B-cell lymphomas presenting at immune-privileged sites. Blood Cancer J 2013;3:e139.

3 Swerdlow SH, Campo E, Pileri SA, et al. The 2016 revision of the World Health Organization classification of lymphoid neoplasms. Blood 2016;127: 2375-2390.

4 Horwitz SM, Zelenetz AD, Gordon LI, et al. NCCN guidelines insights: non-Hodgkin's lymphomas, version 3.2016. J Natl Compr Canc Netw 2016;14: 1067-1079.

5 Anderson KC, Alsina M, Bensinger W, et al. Waldenström's macroglobulinemia/lymphoplasmacytic lymphoma, version 2.2013. J Natl Compr Canc Netw 2012;10:1211-1219.

6 Anderson KC, Alsina M, Atanackovic D, et al. NCCN guidelines insights: multiple myeloma, version 3.2016 . J Natl Compr Canc Netw 2016;14:389-400.
7 Al-Hamadani M, Habermann TM, Cerhan JR, et al. Non-Hodgkin lymphoma subtype distribution, geodemographic patterns, and survival in the US: longitudinal analysis of the National Cancer Data Base from 1998 to 2011. Am J Hematol 2015;90:790-795.

8 Kröber A, Seiler T, Benner A, et al. V(H) mutation status, CD38 expression level, genomic aberrations, and survival in chronic lymphocytic leukemia. Blood 2002;100:1410-1416.

9 Chiaretti S, Marinelli M, Del Giudice I, et al. NOTCH1, SF3B1, BIRC3 and TP53 mutations in patients with chronic lymphocytic leukemia undergoing first-line treatment: correlation with biological parameters and response to treatment. Leuk Lymphoma 2014;55:2785-2792.

10 Cortese D, Sutton LA, Cahill N, et al. On the way towards a 'CLL prognostic index': focus on TP53, BIRC3, SF3B1, NOTCH1 and MYD88 in a populationbased cohort. Leukemia 2014;28:710-713.

11 Xia Y, Fan L, Wang L, et al. Frequencies of SF3B1, NOTCH1, MYD88, BIRC3 and IGHV mutations and TP53 disruptions in Chinese with chronic lymphocytic leukemia: disparities with Europeans. Oncotarget 2015;6:5426-5434.

12 Zenz T, Mertens D, Küppers R, et al. From pathogenesis to treatment of chronic lymphocytic leukaemia. Nat Rev Cancer 2010;10:37-50.

13 Wang L, Lawrence MS, Wan Y, et al. SF3B1 and other novel cancer genes in chronic lymphocytic leukemia. N Engl J Med 2011;365:2497-2506.

14 Oscier DG, Rose-Zerilli MJ, Winkelmann N, et al. The clinical significance of NOTCH1 and SF3B1 mutations in the UK LRF CLL4 trial. Blood 2013;121: $468-475$.

15 Rossi D, Rasi S, Fabbri G, et al. Mutations of NOTCH1 are an independent predictor of survival in chronic lymphocytic leukemia. Blood 2012;119:521-529.

16 Döhner H, Stilgenbauer S, James MR, et al. 11q deletions identify a new subset of B-cell chronic lymphocytic leukemia characterized by extensive nodal involvement and inferior prognosis. Blood 1997;89: 2516-2522.

17 Baliakas P, Hadzidimitriou A, Sutton LA, et al. Recurrent mutations refine prognosis in chronic lymphocytic leukemia. Leukemia 2015;29:329-336.

18 Rossi D, Bruscaggin A, Spina V, et al. Mutations of the SF3B1 splicing factor in chronic lymphocytic leukemia: association with progression and fludarabine-refractoriness. Blood 2011;118:6904-6908.

19 Fabbri G, Khiabanian H, Holmes AB, et al. Genetic lesions associated with chronic lymphocytic leukemia transformation to Richter syndrome. J Exp Med 2013;210:2273-2288.

20 Jeromin S, Weissmann S, Haferlach C, et al. SF3B1 mutations correlated to cytogenetics and mutations in NOTCH1, FBXW7, MYD88, XPO1 and TP53 in 1160 untreated CLL patients. Leukemia 2014;28:108-117.

21 Austen B, Powell JE, Alvi A, et al. Mutations in the ATM gene lead to impaired overall and treatment-free survival that is independent of IGVH mutation status in patients with B-CLL. Blood 2005;106:3175-3182.

22 Tobin G, Thunberg U, Johnson A, et al. Somatically mutated Ig $\mathrm{V}(\mathrm{H}) 3-21$ genes characterize a new subset of chronic lymphocytic leukemia. Blood 2002;99: 2262-2264

23 Guarini A, Marinelli M, Tavolaro S, et al. ATM gene alterations in chronic lymphocytic leukemia patients 
induce a distinct gene expression profile and predict disease progression. Haematologica 2012;97:47-55.

24 Uziel T, Savitsky K, Platzer M, et al. Genomic organization of the ATM gene. Genomics 1996;33:317-320.

25 Bredemeyer AL, Sharma GG, Huang CY, et al. ATM stabilizes DNA double-strand-break complexes during V(D)J recombination. Nature 2006;442:466-470.

26 Stankovic T, Stewart GS, Fegan C, et al. Ataxia telangiectasia mutated-deficient B-cell chronic lymphocytic leukemia occurs in pregerminal center cells and results in defective damage response and unrepaired chromosome damage. Blood 2002;99:300-309.

27 Kojima K, Konopleva M, McQueen T, et al. Mdm2 inhibitor Nutlin-3a induces p53-mediated apoptosis by transcription-dependent and transcriptionindependent mechanisms and may overcome Atmmediated resistance to fludarabine in chronic lymphocytic leukemia. Blood 2006;108:993-1000.

28 Bertrand MJ, Lippens S, Staes A, et al. cIAP1/2 are direct E3 ligases conjugating diverse types of ubiquitin chains to receptor interacting proteins kinases 1 to 4 (RIP1-4). PLoS ONE 2011;6:e22356.

29 Rossi D, Fangazio M, Rasi S, et al. Disruption of BIRC3 associates with fludarabine chemorefractoriness in TP53 wild-type chronic lymphocytic leukemia. Blood 2012;119:2854-2862.

30 Zarnegar BJ, Wang Y, Mahoney DJ, et al. Noncanonical NF-kappaB activation requires coordinated assembly of a regulatory complex of the adaptors cIAP1, CIAP2, TRAF2 and TRAF3 and the kinase NIK. Nat Immunol 2008;9:1371-1378.

31 Foa R, Del Giudice I, Guarini A, et al. Clinical implications of the molecular genetics of chronic lymphocytic leukemia. Haematologica 2013;98:675-685.

32 Conze DB, Zhao Y, Ashwell JD. Non-canonical NF-кB activation and abnormal $\mathrm{B}$ cell accumulation in mice expressing ubiquitin protein ligase-inactive c-IAP2. PLoS Biol 2010;8:e1000518.

33 Conze DB, Zhao Y, Ashwell JD. Correction: Noncanonical NF- $\mathrm{KB}$ activation and abnormal B cell accumulation in mice expressing ubiquitin protein ligase-inactive c-IAP2. PLoS Biol 2016;14:e1002502.

34 Rossi D, Deaglio S, Dominguez-Sola D, et al. Alteration of BIRC3 and multiple other NF-кB pathway genes in splenic marginal zone lymphoma. Blood 2011;118:4930-4934.

35 Puiggros A, Blanco G, Espinet B. Genetic abnormalities in chronic lymphocytic leukemia: where we are and where we go. Biomed Res Int 2014;2014:435983.

36 Martínez-Trillos A, Pinyol M, Navarro A, et al. Mutations in TLR/MYD88 pathway identify a subset of young chronic lymphocytic leukemia patients with favorable outcome. Blood 2014;123:3790-3796.

37 Guièze R, Wu CJ. Genomic and epigenomic heterogeneity in chronic lymphocytic leukemia. Blood 2015;126:445-453.

38 Puente XS, Beà S, Valdés-Mas R, et al. Non-coding recurrent mutations in chronic lymphocytic leukaemia. Nature 2015;526:519-524.

39 Puente XS, Pinyol M, Quesada V, et al. Wholegenome sequencing identifies recurrent mutations in chronic lymphocytic leukaemia. Nature 2011;475: 101-105.

40 Kiel MJ, Velusamy T, Betz BL, et al. Whole-genome sequencing identifies recurrent somatic NOTCH2 mutations in splenic marginal zone lymphoma. J Exp Med 2012;209:1553-1565.
41 Rossi D, Trifonov V, Fangazio M, et al. The coding genome of splenic marginal zone lymphoma: activation of NOTCH2 and other pathways regulating marginal zone development. J Exp Med 2012;209:1537-1551.

42 Fabbri G, Rasi S, Rossi D, et al. Analysis of the chronic lymphocytic leukemia coding genome: role of NOTCH1 mutational activation. J Exp Med 2011;208: 1389-1401.

43 Groth C, Fortini ME. Therapeutic approaches to modulating Notch signaling: current challenges and future prospects. Semin Cell Dev Biol 2012;23:465-472.

44 Wall S, Woyach JA. Chronic lymphocytic leukemia and other lymphoproliferative disorders. Clin Geriatr Med 2016;32:175-189.

45 Quesada V, Conde L, Villamor N, et al. Exome sequencing identifies recurrent mutations of the splicing factor SF3B1 gene in chronic lymphocytic leukemia. Nat Genet 2012;44:47-52.

46 Zenz T, Eichhorst B, Busch R, et al. TP53 mutation and survival in chronic lymphocytic leukemia. J Clin Oncol 2010;28:4473-4479.

47 Döhner H, Fischer K, Bentz M, et al. p53 gene deletion predicts for poor survival and non-response to therapy with purine analogs in chronic B-cell leukemias. Blood 1995;85:1580-1589.

48 Klein U, Dalla-Favera R. Germinal centres: role in B-cell physiology and malignancy. Nat Rev Immunol 2008;8:22-33.

49 Stilgenbauer S, Schnaiter A, Paschka P, et al. Gene mutations and treatment outcome in chronic lymphocytic leukemia: results from the CLL8 trial. Blood 2014;123:3247-3254.

50 Döhner H, Stilgenbauer S, Benner A, et al. Genomic aberrations and survival in chronic lymphocytic leukemia. N Engl J Med 2000;343:1910-1916.

51 Catovsky D, Richards S, Matutes E, et al. Assessment of fludarabine plus cyclophosphamide for patients with chronic lymphocytic leukaemia (the LRF CLL4 Trial): a randomised controlled trial. Lancet 2007;370: 230-239.

52 Grever MR, Lucas DM, Dewald GW, et al. Comprehensive assessment of genetic and molecular features predicting outcome in patients with chronic lymphocytic leukemia: results from the US Intergroup Phase III Trial E2997. J Clin Oncol 2007;25:799-804.

53 Rossi D, Cerri M, Deambrogi C, et al. The prognostic value of TP53 mutations in chronic lymphocytic leukemia is independent of Del17p13: implications for overall survival and chemorefractoriness. Clin Cancer Res 2009;15:995-1004.

54 Pospisilova S, Gonzalez D, Malcikova J, et al. ERIC recommendations on TP53 mutation analysis in chronic lymphocytic leukemia. Leukemia 2012;26: 1458-1461.

55 Byrd JC, Furman RR, Coutre SE, et al. Targeting BTK with ibrutinib in relapsed chronic lymphocytic leukemia. N Engl J Med 2013;369:32-42.

56 Woyach JA, Furman RR, Liu TM, et al. Resistance mechanisms for the Bruton's tyrosine kinase inhibitor ibrutinib. N Engl J Med 2014;370:2286-2294.

57 Jethwa A, Hüllein J, Stolz T, et al. Targeted resequencing for analysis of clonal composition of recurrent gene mutations in chronic lymphocytic leukaemia. $\mathrm{Br}$ J Haematol 2013;163:496-500.

58 Landau DA, Carter SL, Stojanov P, et al. Evolution and impact of subclonal mutations in chronic lymphocytic leukemia. Cell 2013;152:714-726. 
59 Liu L, Wang H, Chen Y, et al. Splenic marginal zone lymphoma: a population-based study on the 20012008 incidence and survival in the United States. Leuk Lymphoma 2013;54:1380-1386.

60 Olszewski AJ. Survival outcomes with and without splenectomy in splenic marginal zone lymphoma. Am J Hematol 2012;87:E119-E122.

61 Perrone S, D'Elia GM, Annechini G, et al. Splenic marginal zone lymphoma: prognostic factors, role of watch and wait policy, and other therapeutic approaches in the rituximab era. Leuk Res 2016;44: 53-60.

62 Piva R, Deaglio S, Famà R, et al. The Krüppel-like factor 2 transcription factor gene is recurrently mutated in splenic marginal zone lymphoma. Leukemia 2015;29:503-507.

63 Martínez N, Almaraz C, Vaqué JP, et al. Whole-exome sequencing in splenic marginal zone lymphoma reveals mutations in genes involved in marginal zone differentiation. Leukemia 2014;28:1334-1340.

64 Parry M, Rose-Zerilli MJ, Ljungstrom V, et al. Genetics and prognostication in splenic marginal zone lymphoma: revelations from deep sequencing. Clin Cancer Res 2015;21:4174-4183.

65 Lloret E, Mollejo M, Mateo MS, et al. Splenic marginal zone lymphoma with increased number of blasts: an aggressive variant? Hum Pathol 1999;30:1153-1160.

66 Kakinoki Y, Kubota H, Sakurai H, et al. Blastic transformation after splenectomy in a patient with nonvillous splenic marginal zone lymphoma with p53 overexpression: a case report. Int J Hematol 2005;81:417-420.

67 Viaggi S, Abbondandolo A, Carbone M, et al. Uncommon cytogenetic findings in a case of splenic marginal zone lymphoma with aggressive clinical course. Cancer Genet Cytogenet 2004;148:133-136.

68 Shields JM, Yang VW. Two potent nuclear localization signals in the gut-enriched Krüppel-like factor define a subfamily of closely related Krüppel proteins. J Biol Chem 1997;272:18504-18507.

69 Bikos V, Darzentas N, Hadzidimitriou A, et al. Over $30 \%$ of patients with splenic marginal zone lymphoma express the same immunoglobulin heavy variable gene: ontogenetic implications. Leukemia 2012;26:1638-1646.

70 Tiacci E, Trifonov V, Schiavoni G, et al. BRAF mutations in hairy-cell leukemia. N Engl J Med 2011;364: 2305-2315.

71 Boyd EM, Bench AJ, van 't Veer MB, et al. High resolution melting analysis for detection of BRAF exon 15 mutations in hairy cell leukaemia and other lymphoid malignancies. Br J Haematol 2011;155: 609-612.

72 Okada K, Kunitomi A, Sakai K, et al. Hairy cell leukemia with systemic lymphadenopathy: detection of BRAF mutations in both lymph node and peripheral blood specimens. Intern Med 2015;54:1397-1402.

73 Eroglu Z, Ribas A. Combination therapy with BRAF and MEK inhibitors for melanoma: latest evidence and place in therapy. Ther Adv Med Oncol 2016;8: 48-56.

74 Chihara D, Kantarjian H, O'Brien S, et al. Long-term durable remission by cladribine followed by rituximab in patients with hairy cell leukaemia: update of a phase II trial. Br J Haematol 2016;174:760-766.

75 Hockley SL, Else M, Morilla A, et al. The prognostic impact of clinical and molecular features in hairy cell leukaemia variant and splenic marginal zone lymphoma. Br J Haematol 2012;158:347-354.

76 Arons E, Suntum T, Stetler-Stevenson M, et al. VH4$34+$ hairy cell leukemia, a new variant with poor prognosis despite standard therapy. Blood 2009;114: 4687-4695.

77 Waterfall JJ, Arons E, Walker RL, et al. High prevalence of MAP2K1 mutations in variant and IGHV4-34expressing hairy-cell leukemias. Nat Genet 2014;46: 8-10.

78 Ngo VN, Young RM, Schmitz R, et al. Oncogenically active MYD88 mutations in human lymphoma. Nature 2011;470:115-119.

79 Treon SP, Xu L, Yang G, et al. MYD88 L265P somatic mutation in Waldenström's macroglobulinemia. N Engl J Med 2012;367:826-833.

$80 \mathrm{Xu} \mathrm{L}$, Hunter ZR, Yang G, et al. MYD88 L265P in Waldenström macroglobulinemia, immunoglobulin $\mathrm{M}$ monoclonal gammopathy, and other B-cell lymphoproliferative disorders using conventional and quantitative allele-specific polymerase chain reaction. Blood 2013;121:2051-2058.

81 Varettoni M, Arcaini L, Zibellini S, et al. Prevalence and clinical significance of the MYD88 (L265P) somatic mutation in Waldenstrom's macroglobulinemia and related lymphoid neoplasms. Blood 2013;121:2522-2528.

82 Jiménez C, MeC Chillón, Balanzategui A, et al. Detection of MYD88 L265P mutation by real-time allelespecific oligonucleotide polymerase chain reaction. Appl Immunohistochem Mol Morphol 2014;22:768-773.

83 Ansell SM, Hodge LS, Secreto FJ, et al. Activation of TAK1 by MYD88 L265P drives malignant B-cell growth in non-Hodgkin lymphoma. Blood Cancer J 2014;4:e183.

84 Thelander EF, Walsh SH, Thorsélius M, et al. Mantle cell lymphomas with clonal immunoglobulin $\mathrm{V}(\mathrm{H}) 3-$ 21 gene rearrangements exhibit fewer genomic imbalances than mantle cell lymphomas utilizing other immunoglobulin $\mathrm{V}(\mathrm{H})$ genes. Mod Pathol 2005;18: 331-339.

85 Lenz G, Wright G, Dave SS, et al. Stromal gene signatures in large-B-cell lymphomas. N Engl J Med 2008;359:2313-2323.

86 Gachard N, Parrens M, Soubeyran I, et al. IGHV gene features and MYD88 L265P mutation separate the three marginal zone lymphoma entities and Waldenström macroglobulinemia/lymphoplasmacytic lymphomas. Leukemia 2013;27:183-189.

87 Schmidt J, Federmann B, Schindler N, et al. MYD88 L265P and CXCR4 mutations in lymphoplasmacytic lymphoma identify cases with high disease activity. Br J Haematol 2015;169:795-803.

88 Cao Y, Hunter ZR, Liu X, et al. The WHIM-like CXCR4(S338X) somatic mutation activates AKT and ERK, and promotes resistance to ibrutinib and other agents used in the treatment of Waldenstrom's Macroglobulinemia. Leukemia 2015;29:169-176.

89 Hunter ZR, Xu L, Yang G, et al. The genomic landscape of Waldenstrom macroglobulinemia is characterized by highly recurring MYD88 and WHIM-like CXCR4 mutations, and small somatic deletions associated with B-cell lymphomagenesis. Blood 2014;123:1637-1646.

90 Morgan GJ, Walker BA, Davies FE. The genetic architecture of multiple myeloma. Nat Rev Cancer 2012;12:335-348. 
91 Lohr JG, Stojanov P, Carter SL, et al. Widespread genetic heterogeneity in multiple myeloma: implications for targeted therapy. Cancer Cell 2014;25:91-101.

92 Gertz MA, Lacy MQ, Dispenzieri A, et al. Clinical implications of $\mathrm{t}(11 ; 14)(\mathrm{q} 13 ; \mathrm{q} 32), \mathrm{t}(4 ; 14)(\mathrm{p} 16.3 ; \mathrm{q} 32)$, and $-17 \mathrm{p} 13$ in myeloma patients treated with highdose therapy. Blood 2005;106:2837-2840.

93 Shaughnessy JD, Zhan F, Burington BE, et al. A validated gene expression model of high-risk multiple myeloma is defined by deregulated expression of genes mapping to chromosome 1. Blood 2007;109: 2276-2284.

94 Walker BA, Boyle EM, Wardell CP, et al. Mutational spectrum, copy number changes, and outcome: results of a sequencing study of patients with newly diagnosed myeloma. J Clin Oncol 2015;33:3911-3920.

95 Trudel S, Li ZH, Wei E, et al. CHIR-258, a novel, multitargeted tyrosine kinase inhibitor for the potential treatment of $\mathrm{t}(4 ; 14)$ multiple myeloma. Blood 2005;105:2941-2948.

96 Cirstea D, Hideshima T, Santo L, et al. Small-molecule multi-targeted kinase inhibitor RGB-286638 triggers P53-dependent and -independent anti-multiple myeloma activity through inhibition of transcriptional CDKs. Leukemia 2013;27:2366-2375.

97 Nooka AK, Kaufman JL, Muppidi S, et al. Consolidation and maintenance therapy with lenalidomide, bortezomib and dexamethasone (RVD) in high-risk myeloma patients. Leukemia 2014;28:690-693.

98 Levine EG, Arthur DC, Machnicki J, et al. Four new recurring translocations in non-Hodgkin lymphoma. Blood 1989;74:1796-1800.

99 Isaacson PG, Du MQ. MALT lymphoma: from morphology to molecules. Nat Rev Cancer 2004;4:644-653.

100 Sanchez-Izquierdo D, Buchonnet G, Siebert R, et al. MALT1 is deregulated by both chromosomal translocation and amplification in B-cell non-Hodgkin lymphoma. Blood 2003;101:4539-4546.

$101 \mathrm{Hu}$ S, Du MQ, Park SM, et al. cIAP2 is a ubiquitin protein ligase for BCL10 and is dysregulated in mucosa-associated lymphoid tissue lymphomas. J Clin Invest 2006;116:174-181.

102 Johansson P, Klein-Hitpass L, Grabellus F, et al. Recurrent mutations in NF- $\mathrm{BB}$ pathway components, KMT2D, and NOTCH1/2 in ocular adnexal MALTtype marginal zone lymphomas. Oncotarget 2016;7: 62627-62639.

103 Jung H, Yoo HY, Lee SH, et al. The mutational landscape of ocular marginal zone lymphoma identifies frequent alterations in TNFAIP3 followed by mutations in TBL1XR1 and CREBBP. Oncotarget 2017;8: 17038-17049.

104 Traverse-Glehen A, Davi F, Ben Simon E, et al. Analysis of $\mathrm{VH}$ genes in marginal zone lymphoma reveals marked heterogeneity between splenic and nodal tumors and suggests the existence of clonal selection. Haematologica 2005;90:470-478.

105 Spina V, Khiabanian H, Messina M, et al. The genetics of nodal marginal zone lymphoma. Blood 2016;128: 1362-1373.

106 Ortiz B, Fabius AW, Wu WH, et al. Loss of the tyrosine phosphatase PTPRD leads to aberrant STAT3 activation and promotes gliomagenesis. Proc Natl Acad Sci USA 2014;111:8149-8154.

107 Morin RD, Mendez-Lago M, Mungall AJ, et al. Frequent mutation of histone-modifying genes in non-Hodgkin lymphoma. Nature 2011;476:298-303.
108 Lunning MA, Green MR. Mutation of chromatin modifiers; an emerging hallmark of germinal center B-cell lymphomas. Blood Cancer J 2015;5:e361.

109 Pasqualucci L, Khiabanian H, Fangazio M, et al. Genetics of follicular lymphoma transformation. Cell Rep 2014;6:130-140.

110 Rossi D, Berra E, Cerri M, et al. Aberrant somatic hypermutation in transformation of follicular lymphoma and chronic lymphocytic leukemia to diffuse large B-cell lymphoma. Haematologica 2006; 91:1405-1409.

111 Kridel R, Chan FC, Mottok A, et al. Histological transformation and progression in follicular lymphoma: a clonal evolution study. PLoS Med 2016;13: e1002197.

112 Tsujimoto Y, Cossman J, Jaffe E, Croce CM. Involvement of the bcl-2 gene in human follicular lymphoma. Science 1985;228:1440-1443.

113 Cleary ML, Sklar J. Nucleotide sequence of a $t(14 ; 18)$ chromosomal breakpoint in follicular lymphoma and demonstration of a breakpoint-cluster region near a transcriptionally active locus on chromosome 18. Proc Natl Acad Sci USA 1985;82:7439-7443.

114 Cotter FE, Price C, Meerabux J, et al. Direct sequence analysis of $14 q+$ and 18q- chromosome junctions at the MBR and MCR revealing clustering within the MBR in follicular lymphoma. Ann Oncol 1991;2 (Suppl 2):93-97.

115 Horsman DE, Gascoyne RD, Coupland RW, et al. Comparison of cytogenetic analysis, southern analysis, and polymerase chain reaction for the detection of $\mathrm{t}(14 ; 18)$ in follicular lymphoma. Am J Clin Pathol 1995;103:472-478.

116 Salaverria I, Martin-Guerrero I, Wagener R, et al. A recurrent $11 \mathrm{q}$ aberration pattern characterizes a subset of MYC-negative high-grade B-cell lymphomas resembling Burkitt lymphoma. Blood 2014;123:1187-1198.

117 Ferreiro JF, Morscio J, Dierickx D, et al. Posttransplant molecularly defined Burkitt lymphomas are frequently MYC-negative and characterized by the 11q-gain/loss pattern. Haematologica 2015;100: e275-e279.

118 Wiestner A, Tehrani M, Chiorazzi M, et al. Point mutations and genomic deletions in CCND1 create stable truncated cyclin D1 mRNAs that are associated with increased proliferation rate and shorter survival. Blood 2007;109:4599-4606.

119 O'Shea D, O'Riain C, Taylor C, et al. The presence of TP53 mutation at diagnosis of follicular lymphoma identifies a high-risk group of patients with shortened time to disease progression and poorer overall survival. Blood 2008;112:3126-3129.

120 Salaverria I, Philipp C, Oschlies I, et al. Translocations activating IRF4 identify a subtype of germinal centerderived B-cell lymphoma affecting predominantly children and young adults. Blood 2011;118:139-147.

121 Lorsbach RB, Shay-Seymore D, Moore J, et al. Clinicopathologic analysis of follicular lymphoma occurring in children. Blood 2002;99:1959-1964.

122 Louissaint A, Ackerman AM, Dias-Santagata D, et al. Pediatric-type nodal follicular lymphoma: an indolent clonal proliferation in children and adults with high proliferation index and no BCL2 rearrangement. Blood 2012;120:2395-2404.

123 Martin-Guerrero I, Salaverria I, Burkhardt B, et al. Recurrent loss of heterozygosity in 1p36 associated with TNFRSF14 mutations in IRF4 translocation 
negative pediatric follicular lymphomas. Haematologica 2013;98:1237-1241.

124 Schmidt J, Gong S, Marafioti T, et al. Genome-wide analysis of pediatric-type follicular lymphoma reveals low genetic complexity and recurrent alterations of TNFRSF14 gene. Blood 2016;128:1101-1111.

125 Louissaint A, Schafernak KT, Geyer JT, et al. Pediatric-type nodal follicular lymphoma: a biologically distinct lymphoma with frequent MAPK pathway mutations. Blood 2016;128:1093-1100.

126 Katzenberger T, Kalla J, Leich E, et al. A distinctive subtype of $\mathrm{t}(14 ; 18)$-negative nodal follicular nonHodgkin lymphoma characterized by a predominantly diffuse growth pattern and deletions in the chromosomal region 1p36. Blood 2009;113:1053-1061.

127 Siddiqi IN, Friedman J, Barry-Holson KQ, et al. Characterization of a variant of $\mathrm{t}(14 ; 18)$ negative nodal diffuse follicular lymphoma with CD23 expression, 1p36/TNFRSF14 abnormalities, and STAT6 mutations. Mod Pathol 2016;29:570-581.

128 Goy A, Kahl B. Mantle cell lymphoma: the promise of new treatment options. Crit Rev Oncol Hematol 2011;80:69-86.

129 Orchard J, Garand R, Davis Z, et al. A subset of $\mathrm{t}$ $(11 ; 14)$ lymphoma with mantle cell features displays mutated IgVH genes and includes patients with good prognosis, nonnodal disease. Blood 2003;101: 4975-4981.

130 Navarro A, Clot G, Royo C, et al. Molecular subsets of mantle cell lymphoma defined by the IGHV mutational status and SOX11 expression have distinct biologic and clinical features. Cancer Res 2012;72: 5307-5316.

131 Ondrejka SL, Lai R, Smith SD, et al. Indolent mantle cell leukemia: a clinicopathological variant characterized by isolated lymphocytosis, interstitial bone marrow involvement, kappa light chain restriction, and good prognosis. Haematologica 2011;96:1121-1127.

132 Royo C, Navarro A, Clot G, et al. Non-nodal type of mantle cell lymphoma is a specific biological and clinical subgroup of the disease. Leukemia 2012;26: 1895-1898.

133 Martin P, Chadburn A, Christos P, et al. Outcome of deferred initial therapy in mantle-cell lymphoma. J Clin Oncol 2009;27:1209-1213.

134 Fernàndez V, Salamero O, Espinet B, et al. Genomic and gene expression profiling defines indolent forms of mantle cell lymphoma. Cancer Res 2010;70: 1408-1418.

135 Kridel R, Meissner B, Rogic S, et al. Whole transcriptome sequencing reveals recurrent NOTCH1 mutations in mantle cell lymphoma. Blood 2012;119: 1963-1971.

136 Rubio-Moscardo F, Climent J, Siebert R, et al. Mantlecell lymphoma genotypes identified with CGH to BAC microarrays define a leukemic subgroup of disease and predict patient outcome. Blood 2005;105: 4445-4454.

137 Halldórsdóttir AM, Lundin A, Murray F, et al. Impact of TP53 mutation and 17p deletion in mantle cell lymphoma. Leukemia 2011;25:1904-1908.

138 Beà S, Valdés-Mas R, Navarro A, et al. Landscape of somatic mutations and clonal evolution in mantle cell lymphoma. Proc Natl Acad Sci USA 2013;110: 18250-18255.

139 Zhang J, Jima $\mathrm{D}$, Moffitt $\mathrm{AB}$, et al. The genomic landscape of mantle cell lymphoma is related to the epigenetically determined chromatin state of normal B cells. Blood 2014;123:2988-2996.

140 Medeiros LJ, Van Krieken JH, Jaffe ES, et al. Association of bcl-1 rearrangements with lymphocytic lymphoma of intermediate differentiation. Blood 1990;76: 2086-2090.

141 Tsujimoto Y, Yunis J, Onorato-Showe L, et al. Molecular cloning of the chromosomal breakpoint of B-cell lymphomas and leukemias with the $\mathrm{t}(11 ; 14)$ chromosome translocation. Science 1984;224:1403-1406.

142 Tsujimoto Y, Jaffe E, Cossman J, et al. Clustering of breakpoints on chromosome 11 in human B-cell neoplasms with the $t(11 ; 14)$ chromosome translocation. Nature 1985;315:340-343.

143 Rahal R, Frick M, Romero R, et al. Pharmacological and genomic profiling identifies NF- $\mathrm{kB}$-targeted treatment strategies for mantle cell lymphoma. Nat Med 2014;20:87-92.

144 Mohanty A, Sandoval N, Das M, et al. CCND1 mutations increase protein stability and promote ibrutinib resistance in mantle cell lymphoma. Oncotarget 2016;7:73558-73572.

145 Slotta-Huspenina J, Koch I, de Leval L, et al. The impact of cyclin D1 mRNA isoforms, morphology and p53 in mantle cell lymphoma: p53 alterations and blastoid morphology are strong predictors of a high proliferation index. Haematologica 2012;97: 1422-1430.

146 Correa JG, Cibeira MT, Tovar N, et al. Prevalence and prognosis implication of MYD88 L265P mutation in IgM monoclonal gammopathy of undetermined significance and smouldering Waldenström macroglobulinaemia. Br J Haematol 2016; doi:10.1111/bjh.14266.

147 Greiner TC, Dasgupta C, Ho VV, et al. Mutation and genomic deletion status of ataxia telangiectasia mutated (ATM) and p53 confer specific gene expression profiles in mantle cell lymphoma. Proc Natl Acad Sci USA 2006;103:2352-2357.

148 Hartmann EM, Campo E, Wright G, et al. Pathway discovery in mantle cell lymphoma by integrated analysis of high-resolution gene expression and copy number profiling. Blood 2010;116:953-961.

149 Beà S, Ribas M, Hernández JM, et al. Increased number of chromosomal imbalances and high-level DNA amplifications in mantle cell lymphoma are associated with blastoid variants. Blood 1999;93:4365-4374.

150 Thorsélius M, Walsh S, Eriksson I, et al. Somatic hypermutation and $\mathrm{V}(\mathrm{H})$ gene usage in mantle cell lymphoma. Eur J Haematol 2002;68:217-224.

151 Rosenwald A, Wright G, Leroy K, et al. Molecular diagnosis of primary mediastinal B cell lymphoma identifies a clinically favorable subgroup of diffuse large B cell lymphoma related to Hodgkin lymphoma. J Exp Med 2003;198:851-862.

152 Alizadeh AA, Eisen MB, Davis RE, et al. Distinct types of diffuse large B-cell lymphoma identified by gene expression profiling. Nature 2000;403:503-511.

153 Staudt LM, Dave S. The biology of human lymphoid malignancies revealed by gene expression profiling. Adv Immunol 2005;87:163-208.

154 Wilson WH, Dunleavy K, Pittaluga S, et al. Phase II study of dose-adjusted EPOCH and rituximab in untreated diffuse large B-cell lymphoma with analysis of germinal center and post-germinal center biomarkers. J Clin Oncol 2008;26:2717-2724.

155 Wilson WH, Jung SH, Porcu P, et al. A Cancer and Leukemia Group B multi-center study of DA-EPOCH- 
rituximab in untreated diffuse large B-cell lymphoma with analysis of outcome by molecular subtype. Haematologica 2012;97:758-765.

156 Lenz G, Davis RE, Ngo VN, et al. Oncogenic CARD11 mutations in human diffuse large B cell lymphoma. Science 2008;319:1676-1679.

157 Davis RE, Ngo VN, Lenz G, et al. Chronic active B-cellreceptor signalling in diffuse large B-cell lymphoma. Nature 2010;463:88-92.

158 Compagno M, Lim WK, Grunn A, et al. Mutations of multiple genes cause deregulation of NF-kappaB in diffuse large B-cell lymphoma. Nature 2009;459: 717-721.

159 Park HY, Lee SB, Yoo HY, et al. Whole-exome and transcriptome sequencing of refractory diffuse large B-cell lymphoma. Oncotarget 2016;7:86433-86445.

160 Young KH, Weisenburger DD, Dave BJ, et al. Mutations in the DNA-binding codons of TP53, which are associated with decreased expression of TRAILreceptor-2, predict for poor survival in diffuse large B-cell lymphoma. Blood 2007;110:4396-4405.

161 Young KH, Leroy K, Møller MB, et al. Structural profiles of TP53 gene mutations predict clinical outcome in diffuse large B-cell lymphoma: an international collaborative study. Blood 2008;112:3088-3098.

162 Rovira J, Karube K, Valera A, et al. MYD88 L265P mutations, but no other variants, identify a subpopulation of DLBCL patients of activated B-cell origin, extranodal involvement, and poor outcome. Clin Cancer Res 2016;22:2755-2764.

163 Lam LT, Wright G, Davis RE, et al. Cooperative signaling through the signal transducer and activator of transcription 3 and nuclear factor-\{kappa\}B pathways in subtypes of diffuse large B-cell lymphoma. Blood 2008;111:3701-3713.

164 Visco C, Tzankov A, Xu-Monette ZY, et al. Patients with diffuse large B-cell lymphoma of germinal center origin with BCL2 translocations have poor outcome, irrespective of MYC status: a report from an International DLBCL rituximab-CHOP Consortium Program Study. Haematologica 2013;98:255-263.

165 Schmitz R, Young RM, Ceribelli M, et al. Burkitt lymphoma pathogenesis and therapeutic targets from structural and functional genomics. Nature 2012;490: 116-120.

166 Weiss LM, Warnke RA, Sklar J, et al. Molecular analysis of the $\mathrm{t}(14 ; 18)$ chromosomal translocation in malignant lymphomas. N Engl J Med 1987;317:1185-1189.

167 Klapper W, Stoecklein H, Zeynalova S, et al. Structural aberrations affecting the MYC locus indicate a poor prognosis independent of clinical risk factors in diffuse large B-cell lymphomas treated within randomized trials of the German High-Grade Non-Hodgkin's Lymphoma Study Group (DSHNHL). Leukemia 2008;22:2226-2229.

168 Otto C, Scholtysik R, Schmitz R, et al. Novel IGH and MYC translocation partners in diffuse large B-cell lymphomas. Genes Chromosomes Cancer 2016;55: 932-943.

169 Li S, Lin P, Young KH, et al. MYC/BCL2 double-hit high-grade B-cell lymphoma. Adv Anat Pathol 2013; 20:315-326.

170 Lim KH, Yang Y, Staudt LM. Pathogenetic importance and therapeutic implications of NF- $\mathrm{KB}$ in lymphoid malignancies. Immunol Rev 2012;246:359-378.

171 Wiestner A. Targeting B-cell receptor signaling for anticancer therapy: the Bruton's tyrosine kinase inhibitor ibrutinib induces impressive responses in B-cell malignancies. J Clin Oncol 2013;31:128-130.

172 Davis RE, Brown KD, Siebenlist U, et al. Constitutive nuclear factor kappaB activity is required for survival of activated B cell-like diffuse large B cell lymphoma cells. J Exp Med 2001;194:1861-1874.

173 Milhollen MA, Traore T, Adams-Duffy J, et al. MLN4924, a NEDD8-activating enzyme inhibitor, is active in diffuse large B-cell lymphoma models: rationale for treatment of $\mathrm{NF}$-\{kappa\}B-dependent lymphoma. Blood 2010;116:1515-1523.

174 Lam LT, Davis RE, Pierce J, et al. Small molecule inhibitors of IkappaB kinase are selectively toxic for subgroups of diffuse large B-cell lymphoma defined by gene expression profiling. Clin Cancer Res 2005;11:28-40.

175 Leroy K, Haioun C, Lepage E, et al. p53 gene mutations are associated with poor survival in low and low-intermediate risk diffuse large B-cell lymphomas. Ann Oncol 2002;13:1108-1115.

176 Kerbauy FR, Colleoni GW, Saad ST, et al. Detection and possible prognostic relevance of p53 gene mutations in diffuse large B-cell lymphoma. An analysis of 51 cases and review of the literature. Leuk Lymphoma 2004;45:2071-2078

177 Liu YY, Yao SN, Zhao Y, et al. PTEN tumor suppressor plays less prognostic role than P53 tumor suppressor in diffuse large B-cell lymphoma. Leuk Lymphoma 2010;51:1692-1698.

178 Xu-Monette ZY, Wu L, Visco C, et al. Mutational profile and prognostic significance of TP53 in diffuse large B-cell lymphoma patients treated with R-CHOP: report from an International DLBCL RituximabCHOP Consortium Program Study. Blood 2012;120: 3986-3996.

179 Joerger AC, Ang HC, Fersht AR. Structural basis for understanding oncogenic p53 mutations and designing rescue drugs. Proc Natl Acad Sci USA 2006;103: 15056-15061.

180 Joerger AC, Fersht AR. Structural biology of the tumor suppressor p53 and cancer-associated mutants. Adv Cancer Res 2007;97:1-23.

181 Blandino G, Levine AJ, Oren M. Mutant p53 gain of function: differential effects of different p53 mutants on resistance of cultured cells to chemotherapy. Oncogene 1999;18:477-485.

182 Xu-Monette ZY, Medeiros LJ, Li Y, et al. Dysfunction of the TP53 tumor suppressor gene in lymphoid malignancies. Blood 2012;119:3668-3683.

183 Hall PA, McCluggage WG. Assessing p53 in clinical contexts: unlearned lessons and new perspectives. J Pathol 2006;208:1-6.

184 Lozano G, Zambetti GP. What have animal models taught us about the p53 pathway? J Pathol 2005;205: 206-220.

185 Klapproth K, Wirth T. Advances in the understanding of MYC-induced lymphomagenesis. Br J Haematol 2010;149:484-497.

186 Kiaei A, Onsori H, Alijani A, et al. Detection of $\mathrm{t}(8 ; 14)$ $\mathrm{c}-\mathrm{myc} / \mathrm{IgH}$ gene rearrangement by long-distance polymerase chain reaction in patients with diffuse large B-cell lymphoma. Hematol Oncol Stem Cell Ther 2016;9:141-146.

$187 \mathrm{Hu} \mathrm{Z}$, Medeiros LJ, Chen Z, et al. Mantle cell lymphoma with MYC rearrangement: a report of 17 patients. Am J Surg Pathol 2017;41:216-224.

188 Huh YO, Lin KI, Vega F, et al. MYC translocation in chronic lymphocytic leukaemia is associated with 
increased prolymphocytes and a poor prognosis. Br J Haematol 2008;142:36-44.

189 Merchant S, Schlette E, Sanger W, et al. Mature B-cell leukemias with more than 55\% prolymphocytes: report of 2 cases with Burkitt lymphoma-type chromosomal translocations involving c-myc. Arch Pathol Lab Med 2003;127:305-309.

190 Hao S, Sanger W, Onciu M, et al. Mantle cell lymphoma with 8q24 chromosomal abnormalities: a report of 5 cases with blastoid features. Mod Pathol 2002;15:1266-1272.

191 Bellan C, Lazzi S, Hummel M, et al. Immunoglobulin gene analysis reveals 2 distinct cells of origin for EBVpositive and EBV-negative Burkitt lymphomas. Blood 2005;106:1031-1036.

192 Guikema JE, de Boer C, Haralambieva E, et al. IGH switch breakpoints in Burkitt lymphoma: exclusive involvement of noncanonical class switch recombination. Genes Chromosomes Cancer 2006;45:808-819.

193 Piccaluga PP, Navari M, De Falco G, et al. Virusencoded microRNA contributes to the molecular profile of EBV-positive Burkitt lymphomas. Oncotarget 2016;7:224-240.

194 Love C, Sun Z, Jima D, et al. The genetic landscape of mutations in Burkitt lymphoma. Nat Genet 2012;44: 1321-1325.

195 Richter J, Schlesner M, Hoffmann S, et al. Recurrent mutation of the ID3 gene in Burkitt lymphoma identified by integrated genome, exome and transcriptome sequencing. Nat Genet 2012;44:1316-1320.

196 Sander S, Rajewsky K. Burkitt lymphomagenesis linked to MYC plus PI3K in germinal center B cells. Oncotarget 2012;3:1066-1067.

197 Sander S, Calado DP, Srinivasan L, et al. Synergy between PI3K signaling and MYC in Burkitt lymphomagenesis. Cancer Cell 2012;22:167-179.

198 Limon JJ, Fruman DA. B cell receptor signaling: picky about PI3Ks. Sci Signal 2010;3:pe25.

199 Küppers R. The biology of Hodgkin's lymphoma. Nat Rev Cancer 2009;9:15-27.

200 Gunawardana J, Chan FC, Telenius A, et al. Recurrent somatic mutations of PTPN1 in primary mediastinal B cell lymphoma and Hodgkin lymphoma. Nat Genet 2014;46:329-335.

201 Roemer MG, Advani RH, Ligon AH, et al. PD-L1 and PD-L2 genetic alterations define classical Hodgkin lymphoma and predict outcome. J Clin Oncol 2016; 34:2690-2697.

202 Steidl C, Shah SP, Woolcock BW, et al. MHC class II transactivator CIITA is a recurrent gene fusion partner in lymphoid cancers. Nature 2011;471:377-381.
203 Van Dongen JJ, Langerak AW, Brüggemann M, et al. Design and standardization of PCR primers and protocols for detection of clonal immunoglobulin and T-cell receptor gene recombinations in suspect lymphoproliferations: report of the BIOMED-2 Concerted Action BMH4-CT98-3936. Leukemia 2003;17: 2257-2317.

204 Linke B, Bolz I, Fayyazi A, et al. Automated high resolution PCR fragment analysis for identification of clonally rearranged immunoglobulin heavy chain genes. Leukemia 1997;11:1055-1062.

205 Pott C, Tiemann M, Linke B, et al. Structure of Bcl-1 and IgH-CDR3 rearrangements as clonal markers in mantle cell lymphomas. Leukemia 1998;12:1630-1637.

206 Sarasquete ME, García-Sanz R, González D, et al. Minimal residual disease monitoring in multiple myeloma: a comparison between allelic-specific oligonucleotide real-time quantitative polymerase chain reaction and flow cytometry. Haematologica 2005;90: 1365-1372.

207 Xu L, You X, Zheng P, et al. Methodologic considerations in the application of next-generation sequencing of human TRB repertoires for clinical use. J Mol Diagn 2017;19:72-83.

208 Pulsipher MA, Carlson C, Langholz B, et al. IgH-V(D)J NGS-MRD measurement pre- and early post-allotransplant defines very low- and very high-risk ALL patients. Blood 2015;125:3501-3508.

209 Ladetto M, Brüggemann M, Monitillo L, et al. Nextgeneration sequencing and real-time quantitative PCR for minimal residual disease detection in B-cell disorders. Leukemia 2014;28:1299-1307.

210 Faham M, Zheng J, Moorhead M, et al. Deepsequencing approach for minimal residual disease detection in acute lymphoblastic leukemia. Blood 2012;120:5173-5180.

211 Logan AC, Zhang B, Narasimhan B, et al. Minimal residual disease quantification using consensus primers and high-throughput IGH sequencing predicts posttransplant relapse in chronic lymphocytic leukemia. Leukemia 2013;27:1659-1665.

212 Diaz LA, Bardelli A. Liquid biopsies: genotyping circulating tumor DNA. J Clin Oncol 2014;32: 579-586.

213 Rossi D, Diop F, Spaccarotella E, et al. Diffuse large B-cell lymphoma genotyping on the liquid biopsy. Blood 2017;129:1947-1957.

214 Bentley DL, Groudine M. A block to elongation is largely responsible for decreased transcription of c-myc in differentiated HL60 cells. Nature 1986;321: $702-706$. 